\title{
The economy and demand for finance Ph.D.s: 1989-2001
}

\author{
David K. Ding ${ }^{\mathrm{a}, *}$, Sheng-Syan Chen ${ }^{\mathrm{b}}$ \\ ${ }^{a}$ Division of Banking and Finance, Nanyang Business School, Nanyang Technological University, S3-1A-19 \\ Nanyang Avenue, Singapore 639798, Singapore \\ b Yuan Ze University, Taiwan
}

Received 15 August 2003; accepted 12 December 2003

\begin{abstract}
We investigate the demand for new finance Ph.D.s from 1989 to 2001. Three categories of schools (Top 20, Top 21-50, and Other Finance Departments) are explored and the differences between private and public institutions are reported. The demand for assistant professors is the greatest and most institutions require an earned $\mathrm{Ph}$.D. While most do not specify the position type, there is some evidence that tenure-tracked ones are on the rise. The most desired areas of expertise are corporate/business finance, investments, and bank management/financial markets and institutions. The total demand is positively related to the Gross Domestic Product and Dow Jones.
\end{abstract}

(C) 2004 Elsevier B.V. All rights reserved.

JEL classification: $\mathrm{E} 32 ; \mathrm{J} 44$

Keywords: Finance Ph.D.; Academic job market; Areas of expertise

\section{Introduction}

Ph.D.s make up a small segment of the workforce. In 1995, only 1 percent of the US workforce held a Ph.D. degree (Bertin and Zivney, 1991). The typical candidate is a 34-year-old, married, Caucasian male with US citizenship (Bertin et al., 1999). Lahey and Vihtelic (2000) find that the most common rank is full professor. Colleges and universities have been and

\footnotetext{
* Corresponding author. Tel.: +65 6790 4927; fax: +65 67913697.

E-mail address: akyding@ntu.edu.sg (D.K. Ding).
} 
still are the primary employers of Ph.D.s, although non-academic job opportunities have been growing.

No single organization keeps up-to-date statistics on the academic job market. This makes projection difficult and can create problems when economic condition changes. Thus, academics are cautious about predicting the trend of the academic labor market. Tompkins et al. (1996) note that finance doctorates, faculty administrators and prospective doctoral students all have great difficulty in collecting useful information on the expectations and resources associated with new finance faculty positions at the different types of school. They have minimal information that would indicate what is required from the labor market to base their selling efforts.

The existing literature on the academic labor market has examined only limited aspects of the issues. For example, Hansen et al. (1980), Carson and Navarro (1988), and Barbezat (1992) analyze the market for economic doctorates. Numerous studies of undergraduate finance majors and MBAs have also been done. Examples include Grablowsky and Brewer (1975), McCarty and Scherer (1977), and Claiborn and Collins (1978). These studies generally investigate employers' attitude towards finance majors (Grablowsky and Brewer, 1975), the relationship between finance majors and the demand for their services in the financial institutions (McCarty and Scherer, 1977); and the entry-level finance positions in both financial institutions and industrial firms (Claiborn and Collins, 1978).

To date, however, there are few similar studies on the finance doctorate labor market. The only exceptions are those of Taube and MacDonald (1989), Bertin and Zivney (1991), and Cheng and Davidson (1995). Taube and MacDonald use survey data to examine which characteristics of finance job candidates lead to site visits and ultimately to offers. Bertin and Zivney survey finance candidates in the 1991 job market and provide insights on the factors affecting the number of interviews at the Financial Management Association (FMA) Annual Meeting and the salary of accepted offers. Cheng and Davidson mainly focus on the supply side of the finance doctorate market by investigating the characteristics of the job candidates listed in the FMA's Resume Book. Eaton and Nofsinger (2000) examine the reasons why finance faculty decide to accept an academic position. They find that faculty accepting their first academic position ranked teaching load, compatibility with colleagues, and research support as the three most important criteria in accepting the position while relocating faculty ranked teaching load, compatibility with colleagues and base salary as the three most important criteria.

Although these studies are insightful, a comprehensive study on the demand for finance Ph.D.s is largely ignored. Also, hardly any research papers were written to examine if the well-being of the economy affects the academic demand for finance professors. In particular, little or no relevant study was done to find out if more finance professors would be demanded during a boom and whether the demand will decline in times of recession.

The objective of this paper is to provide a current and comprehensive study of the demand for finance Ph.D.s over a 13-year-period from 1989 through 2001. In particular, we examine the new hire market, which is defined as assistant, assistant/associate and open positions. Our purpose is to increase the level of information available to both academic employers and finance doctorates. Our findings should be of interest to academic employ- 
ers by providing a greater understanding of the marketplace, telling something about how the competitors are hiring, and offering a basis for comparing institutional practices. ${ }^{1}$ For current job candidates, our results provide information on what the employers are looking for. Finally, our findings will provide potential doctoral candidates with better information on the trends of the academic job market and their potential job prospects when they graduate.

In this paper, we examine the characteristics of the available positions in the job market for finance Ph.D.s as advertised in the FMA's Directory of Positions Available, Financial Management, the Journal of Business, and the Journal of Finance. We focus our attention on characteristics such as the title of the position, tenure-track or unspecified position, degree requirements, and areas of expertise required. Most of such information comes from the FMA's Directory. We concentrate mainly on the FMA annual job market since this is well recognized as the major recruiting arena in finance and maintains one of the largest clearinghouses for doctoral qualified positions and candidates in the finance community. This restriction will result in a sample that is more homogenous in nature. We also classify the whole sample into three sub-samples: the Top 20, Top 21-50, and Other Finance Departments. This will enable us to find out the differences in demand for finance Ph.D.s among the different categories of schools. In addition, we investigate the impact of the economy on the finance academic market. We separate the schools into private and public universities. The government funds a large portion of the budget of public universities while private universities' funding comes mainly from endowment funds - as well as the high tuition fees charged. Therefore, we will expect a difference in their demand for finance faculties when faced with the same economic situation.

This paper is organized as follows. A review of the related literature is provided in Section 2. In Section 3, we present and discuss our hypotheses. Section 4 describes the data and the methodology. We report the results in Section 5 and Section 6 concludes.

\section{Literature review}

\subsection{General conditions of the overall academic job market for Ph.D.s}

In his study on the overall academic job market for Ph.D.s, Barkume (1997) finds that, although academia remains the primary employer, the proportion of new Ph.D.s who obtained academic appointments after graduation declined steadily from 62 percent in 1974 to 52 percent in 1994. Growth in college enrollments slowed down in the 1970s and colleges and universities greatly reduced their hiring. Consequently, doctoral degree holders faced greater competition for available permanent academic jobs. He concludes that graduates from doctoral programs, including finance doctoral programs, face very stiff competition for faculty positions. Budgetary constraints experienced by the US institutions of higher education have contributed to a weak academic job market. Although the US federal

\footnotetext{
${ }^{1}$ As noted by Bertin and Zivney (1991), even finance department chairpersons can struggle to stay abreast of the latest labor market conditions.
} 
government's share of funding for colleges and universities has held stable since the early 1980s, state support has declined, forcing many institutions to raise tuition and increasingly rely on private funding. Cutbacks had badly affected the job market for hopeful applicants as, in an effort to cut costs, many colleges and universities have adopted various measures, such as increasing class sizes, cutting low priority programs, and relying more heavily on part-time faculty. Decreases in research and development budgets have also had an adverse effect on hiring. Along with lower levels of funding, the US federal government has become more stringent in controlling costs. In the past, the US federal government allocated block grants to an institution; now, however, institutions are required to clearly justify all expenses.

According to Magner (1999), the decrease in the number of doctorates across all faculties should ease the problems that graduates faced in finding tenure-track jobs during the 1990s. She also found that 25 percent of the doctorates in 1998 went into postdoctoral positions, 63 percent already had jobs, while the remaining 12 percent were still uncertain of their career path.

\subsection{The academic job market for finance Ph.D.s}

\subsubsection{Overall conditions}

Throughout most of the 1980s, there was a persistent shortage of new finance academics. The Resume Bookpublished by FMA generally had fewer candidates than available positions. As a result, starting salaries of new finance doctorates have risen. Dyl (1992) reports that, at AACSB-accredited institutions, the mean starting salary rose from US\$ 38,200 in 1985-1986 to US\$ 62,300 in 1991-1992, whereas at unaccredited institutions salaries ranged from US\$ 36,000 to 52,800 over the same time periods. Much of this increase may be attributed to the imbalance between supply and demand, where demand significantly exceeds supply (Cheng and Davidson, 1995).

Much of the early 1990s, however, saw the supply of academics exceeding their demand. Cheng and Davidson (1995) in their study on the supply side of the job market note that the number of job candidates with finance doctorates listed in the FMA's Resume Book increased from 138 in 1986 to 269 in 1992. On the other hand, the number of university positions decreased from 174 in 1986 to 109 in 1992 based on the FMA's Directory of Positions Available. Bertin et al. (1999) find that, between 1991 and 1998, the new-hire finance market in terms of new doctoral candidates and positions offers has shrunk by one-third and one-half, respectively.

Cheng and Davidson (1995) also find that the real salary grew at an increasing rate in the 1980s but declined in the early 1990s. The range in salaries continues to widen substantially lending support to the notion of a segmented finance labor market. Bertin et al. (1999) find that, over the 1990-1995 period, mean starting salaries in accredited institutions rose by roughly 18.5 percent and in unaccredited institutions by only 9.7 percent (Agarwal and Yochum, 2000). Despite the larger shrinkage on the demand side, new-hire finance salaries have risen in nominal terms, although they have declined in real terms. The current market appears to indicate a reversal of this trend with demand exceeding supply and with increasing salary. Such patterns of salary and structural changes are consistent with the cobweb cycle (Freeman, 1975, 1976). 


\subsubsection{The Characteristics}

Taube and MacDonald (1989) examine the characteristics of finance job candidates that lead to campus visits and ultimately to offers. They find that gender, age, publications, academic rank, and the number of interviews at academic meetings influence the probability of campus visits. Candidates' age, gender, academic rank, and the number of campus visits affect the probability of obtaining an employment offer. Bertin and Zivney (1991) show that age and alphabetical listing in the FMA's Resume Book influence the number of interviews at the FMA annual meeting. They also find that the salary of accepted offers is affected by the candidates' nationality and specialization as well as the rankings of their programs. Bertin et al. (1999) confirm that age, teaching experience, specializations, research productivity, and potential are important determinants of the number of offers and the dollar amount of the offers a candidate gets.

Cheng and Davidson (1995) examine the characteristics of the job candidates in the Resume Book. They show that the majority of candidates are new job candidates and are from higher-ranked universities. They also document that around 45 percent of resumes are from international students and that many of them have repeat resumes.

\subsection{The economy and the academic job market}

There is very limited literature on the economy's impact on the academic job market. Yemma (1997) notes that, at a time when overall unemployment has fallen to around 5 percent, high-level scientists experience double-digit unemployment. He also finds that only about 1100 new mathematics Ph.D.s are produced each year in the United States but, through much of this decade, mathematicians have experienced unemployment of more than 14 percent-more than twice the rate of the overall economy.

\section{Discussion of the hypotheses}

In this paper, we focus on the demand side of the academic job market for finance Ph.D. holders. We examine the following four characteristics: the title of position, whether the position is tenure-track or unspecified, degree requirements, and areas of expertise required. ${ }^{2}$ We also explore how the economy's well-being affects the demand for finance faculty. Here, we separate the list of schools into private and public universities. Since they are funded by different sources, we expect the demand for finance Ph.D.s to differ even within the same economic situation. We develop the hypotheses as follows. The health of the economy is represented by three economic variables, namely, the Gross Domestic Product (GDP), Unemployment rate (UNM), and the Dow Jones Industrial Average (DJ).

\footnotetext{
${ }^{2}$ We also collected the data on teaching responsibilities, teaching and industry experience, research and language skill expectations, and salary range. We note that most schools require teaching at both the undergraduate and master's levels. A negligible number of schools, however, provide information on the other items that it becomes impossible to extract any meaningful interpretations to it. These items are therefore excluded from the analysis.
} 


\subsection{The title of position}

The job openings are largely expected to be at the entry-level. In Bertin and Zivney (1991), nearly all positions are at the assistant level, with the exception of the five associate positions offered by Californian schools. Ehrenberg (1992) finds that there is smaller variability across institutions of salaries at the assistant professor than at the full professor level, suggesting that there is greater competition by these institutions at the entry faculty level. At the new assistant professor level, finance is the highest paid discipline, indicating high student demand for instruction and also highly paid non-academic employment opportunities for the faculty. Moreover, Ehrenberg et al. (1991) report that full professors' probability of leaving their institutions is relatively low. Therefore, we hypothesize that the demand for assistant professors is greater than that for associate and full professors.

\subsection{Degree requirements}

Ehrenberg et al. (1998), in their study of Economics Ph.D.s, report that each year only approximately 20-25 percent of the offers go to individuals who have yet to complete their Ph.D. (ABD). Bertin and Zivney (1991), in their survey of the new hire market for finance, find that graduates with position offers have the Ph.D. as their primary type of degree: 65 compared to only four ABDs. Therefore, we hypothesize that there is a preference for graduates with an earned Ph.D. than for those who are ABDs.

\subsection{Type of contract offered}

Within the academic community, faculty rank and tenure are often considered measures of success. However, there seems to be trends of a two-tier labor market. Faculty members are employed on either the tenure-track or non-tenure-track contract. As reported by Ehrenberg (1992), tenure decisions are made during the sixth or seventh year of an individual's initial tenure-track appointment and, especially in doctoral-granting institutions, substantial effort is required to work on research ideas and bring them to fruition before the tenure decision is made.

Tripathy and Ganesh (1996) find that research productivity is considered to be the single most important activity for career advancement, especially for promotions and tenure decisions of Ph.D. degree-granting schools. All tenure-track appointments entail full responsibility for teaching, research, student advising, and performing professional and university service. Appointments can be at the professor, associate or assistant level. Appointments at the professor or associate level normally require an earned doctoral degree or equivalent and demonstrated sustained quality teaching, wide recognition for scholarly activities, and substantial service to the university. At the assistant level, the appointment would require an earned doctorate and potential for excellence in teaching and research.

The traditional career path of a new Ph.D. is to find a tenure-track job, win tenure, and move up the ladder to full professorship. However, Barkume (1997) reports that the number of non-tenure-track faculty members has been growing. Bennett (1994) notes that more institutions are rely on teaching assistants and adjunct faculty while cutting back 
on tenure-track posts. Thus, we hypothesize that the availability of tenure-tracked finance positions is less than non-tenure tracked or unspecified ones.

\subsection{Areas of specialization}

There is growing dominance of international financial institutions in the world's financial markets. With increasing globalization and deregulation, it is expected that there will be a growing demand for graduates who specialize in corporate/business finance, derivatives, financial markets and institutions (FMI), international finance, or investment management. Such courses have been gaining increasing popularity among college students. Tripathy and Ganesh (1996), in their survey on the perceived and desired weights given to teaching, research and service activity find a high research concentration in the mainstream areas of corporate finance, investments, and financial markets and institutions. However, very often, as Ehrenberg (1992) finds out, the choice of undergraduate major is important because, in many fields, students usually enter doctoral study from an undergraduate major in the same, or a closely related field. We therefore hypothesize that the demand for graduates who specialize in corporate/business finance, investments, or financial markets and institutions is stronger than the demand for those who specialize in other areas of finance.

\subsection{The economy's impact on the overall academic job market}

The well-being of the economy has an intimate relationship with the number of jobs available in the market. We investigate the relationship between the health of the economy and the demand for finance Ph.D.s in the academic job market. There are two competing hypothesis in this case. First, when the economy is doing well, the government will be able to allocate more funds to the universities, especially for those that are publicly funded. With a larger budget, universities will be able to hire more professors. Therefore, a rising economy should be associated with a higher demand for finance faculty.

On the other hand, in times of prosperity, there will inevitably be more jobs available in the professional job market. There will be less incentive for graduates to pursue a higher education since highly paid jobs are readily available. With fewer individuals pursuing post-graduate education, there will be a smaller demand for faculty staffing. Thus, when the economy is faring well, there will be smaller demand for finance professors. We investigate which of the two competing hypotheses holds.

\subsection{The economy's impact on private and public universities}

To examine in greater detail, we separate the universities into public and private universities. Public schools all over the world are highly dependent on the government for funds. Coble (2001) finds that higher education budgets are of higher priority now, but are also more subject to economic swings. He highlights that recent figures compiled by the National Conference of State Legislatures in Denver show that higher education's slice of state budget pies (share of aggregate general fund appropriations) dropped from 13.7 percent in fiscal year 1986 to 12.3 percent in fiscal 1996. However, in subsequent years, most legislatures appropriated funds to public colleges and universities at a rate significantly ahead 
of inflation rates. The president of State Policy Research observes that higher education receives higher-than-average appropriations when times are good (as in the late 1990s) and lower-than-average appropriations when times are bad (as in the late 1980s and early 1990s). If the growth rate is remarkable, more funds will be set aside for the public universities to hire more faculty members. However, if the growth rate slows down and government deficits set in, chances are that there will be shrinkage in the budget for universities as well. Therefore, we hypothesize that the demand for finance Ph.D.s among public institutions is positively correlated to the health of the economy. On the other hand, the budget for private schools comes mainly from endowment funds, which are independent of the state of the economy. We expect the demand for finance Ph.D.s among private universities to be unrelated or even negatively related to the economy's well-being.

\section{Data and methodology}

We examine the characteristics of the available positions in the job market for finance Ph.D.s that are advertised in the FMA's Directory of Positions Available, Financial Management, the Journal of Business, and the Journal of Finance. ${ }^{3}$ Any repetitive position announcement in the four sources by the same college or university in the same year is treated as one such position only. If a school advertises for more than one position but does not state exactly how many are demanded, we take the most conservative estimate of two positions demanded. Almost 80 percent of such information is found in the FMA's Directory, with the remaining 20 percent from the three journals. This concentration also results in a sample that is more homogenous in nature as the FMA's Directory format has been standardized as much as possible. ${ }^{4}$ We investigate a 13 -year sample period from 1989 to 2001, inclusive.

Data on such characteristics as the title of position, tenure-track or unspecified position, degree requirements, and areas of expertise required are collected. The appendix shows that the schools are classified into three groups based on the rankings by Fishe (1998) total impact of the research criterion: (1) Top 20 Finance Departments; (2) Top 21-50 Finance Departments and (3) Other Finance Departments (a total of 397 schools). In addition, we classify the universities into public and private schools. This is to see if there are differences in the hiring patterns between the two types of colleges. In particular, we are interested in whether public or private schools hire more finance Ph.D.s when the economy is good and vice versa. We also investigate if public schools employ more entry-level, tenure-track positions than private schools. Furthermore, we find out if public or private schools are more willing to accept ABDs and the types of specialization that each type of institutions

\footnotetext{
${ }^{3}$ One should note that, just because an institution advertises an opening, it does not mean that it will actually fill it. Most ads caution applicants that the job depends on "Budgetary Approval and Appropriate Funding." Certain top institutions may also prefer to hire directly through private arrangements and may not advertise in their positions. Finally, some may list one but have more than one opening.

${ }^{4}$ Note that the number of positions available in the Directory may not be completely accurate as some universities do not recruit at the FMA meetings, while others do not know they have a position at that time to have a listing in the Directory. However, as mentioned by Cheng and Davidson (1995), the Directory is still a reasonably accurate method of estimating the demand for finance faculty candidates.
} 
is keener to fill. The purpose of classifying the data into three categories is to find if there are differences in demand among the different groups of schools. However, there is one limitation: certain top schools may not advertise when they have an opening as they may fill the void through private arrangements.

We first use the Analysis of Variance (ANOVA) procedure to determine if differences exist among two or more groups. This technique analyzes the variance of the data to determine whether we can infer that the population means of the various groups differ, (Keller and Warrack, 1999). Where there is a significant difference among the means, the Tukey multiple comparison technique is then used to ascertain which pair(s) is (are) significantly different. Next, we investigate the relationship between the economy and the demand for all positions, as well as the demand for entry-level positions by applying the following regression model:

$$
\text { Demand }=\beta_{0}+\beta_{1} \text { Year }+\beta_{2} \text { PPDum }+\beta_{3} \text { Rank }+\beta_{4} \text { Economy }+\epsilon
$$

We select three variables, which provide a good representation of the state of the economy. The first variable is the Gross Domestic Product (GDP). We obtain the 13-year data for GDP from the Bureau of Economic Analysis. The Research Department of the Federal Reserve Bank of Cleveland find that information about the relationships between GDP, unemployment, and inflation can be uncovered by separating the data into two distinct components - trend and cyclical.

The trend component can be defined by statistical techniques that draw a smooth line through the central tendency of the data. The cyclical component is then measured as the deviation of the variable from its trend. During recessions, GDP is typically below trend, which implies that the cyclical component exhibits a negative deviation. During booms, the opposite is true, i.e., GDP is above the trend and the cyclical component exhibits a positive deviation. Therefore, there is a positive relationship between GDP and the state of the economy.

The second variable, unemployment rate, tells whether the economy is operating above or below its normal level. In most countries, there is a clear relation between the change in unemployment and GDP growth. High output growth leads to high employment growth as firms hire more workers to produce more. High employment growth leads to a decrease in unemployment. Hence, high output growth is typically associated with a decrease in the unemployment rate. Also, nearing the end of a recession (and hence the start of a recovery), unemployment is typically well above trend showing that the unemployment rate is link between the unemployment rate and the health of the economy as well. This justifies the use of the unemployment rate as one of the three variables. We obtain the 13-year unemployment data from the US Bureau of Labor Statistics.

The third variable we choose is the Dow Jones Industrial Average (DJIA). The data is also obtained from Dow Jones Indexes. DJIA, being the best-known price-weighted series, is the most popular stock-market indicator series. Although it is difficult to conceive that 30 non-randomly selected blue-chip stocks can be representative of the 3000 stocks listed on the New York Stock Exchange (NYSE), beyond the limited number, the stocks included are the largest and most prestigious companies in various industries (Brown and Reilly, 2000). Therefore, DJIA reflects price movements for large, mature, blue chip firms rather than for the typical company listed on the NYSE. The state of the stock index is reflective of the well being of the economy. 
We performed a multiple regression to examine the relationship between the total and entry-level demand for finance academics and the Gross Domestic Product (GDP), Unemployment and Dow Jones Industrial Average (DJ). We use 12 different models in this study. In the first four models, the demand for finance Ph.D.s is regressed against the Gross Domestic Product. We use the current year GDP, the GDP in the past one and two years and well as the GDP in the following year. In the next four models, the demand for finance professors is regressed against the unemployment rate. In the last four models, the demand for finance academics is regressed against the DJ. In the regression model, we control for the year, whether the school is a private or public institution (PPDum $=1$ if public, 0 otherwise), and the ranking of the school. The Top 20 Finance Departments, are assigned a value of 1, the Top 21-50 Finance Departments, a value of 2, and Other Finance Departments, a value of 3 .

\section{Results}

\subsection{The title of position}

\subsubsection{The overall finance hire market}

In Table 1, Panel A1, we report that 60 percent of the overall total position openings are for assistant professors or assistant/associate professors. Open positions represent 30 percent of the total in the 13-year-period. In an average year, there are around 168 openings in all levels, of which 50 advertised openings are for assistant professors only, and 51 are open positions. On average, there is only one opening each for associate and full professor from the total number of positions advertised each year. It is also observed that the openings that specifically exclude assistant professors represent only 11 percent of the total number of positions advertised over the 13 years. Panel A2 and A3 provide the breakdown of the results according to private and public universities, respectively. On average, private universities demand for 44 positions, whereas, public universities demand for 125 positions. On the whole, there are more openings for entry-level positions for both types of schools.

\subsubsection{Top 20 finance departments}

From Table 1, Panel B1, we can see that there are no openings specifically asking for associate professors among the Top 20 Finance Departments. There are also no advertised job openings for both senior positions and department chair and head. This is mainly because the Top 20 Finance Departments frequently appoint internally or use private channels to fill these positions. The bulk of the positions advertised are for assistant professors or open positions. The total number of positions reached the highest level in both 1996 and 2000 at eight positions and the lowest in 1994 and in 1995 at only three positions.

Among private schools (Table 1, Panel B2), an average of 82 percent of the demand is for assistant professors, 11 percent for assistant/associate and 7 percent for the open category. However, majority of the positions demanded by public schools (Table 1, Panel B3) is for the open category (53 percent), followed by assistant professors (33 percent) and assistant/associate (13 percent). 


\subsubsection{Top 21-50 finance departments}

Table 1, Panel C1, shows that most of the position openings among the Top 21-50 Finance Departments seek entry-level assistant professors or are open positions. The assistant level and open positions account for 72 percent of the entire 13-year sample period. In 1992 and 2001, the number of advertised openings for assistant professors reached a high of 10 openings for each of the 2 years and captured 42 percent of the total number of positions available in each of those years. In 1990, there is only one associate professor specifically demanded by the institutions, but such openings are not available in other years. Full pro-

Table 1

Position availability

In Panel A, the overall finance market, there are a total of 447 schools. In Panel B, the Top 20 Finance Departments, there are 20 schools. In Panel C, the Top 21-50 Finance Departments, there are 30 schools. In Panel D, the Other Finance Departments, there are a total of 397 schools. The total number of openings advertised for each position in each year of the sample period 1989-2001 is listed and their percentages are calculated accordingly. Arithmetic means and standard deviation values are also computed. Panel E compares the demand for the various ranks among the three groups of schools. Panel F displays the results for the tests for differences in ranks demanded within each group. Panel $\mathrm{G}$ tests for differences between the private and public universities.

\begin{tabular}{|c|c|c|c|c|c|c|c|c|c|c|c|c|c|c|c|c|c|c|}
\hline \multicolumn{19}{|c|}{ Title of Positions } \\
\hline \multicolumn{3}{|c|}{ Assistant } & \multicolumn{2}{|c|}{ Associate } & \multicolumn{2}{|c|}{ Assist/Assoc } & \multicolumn{2}{|c|}{ Full } & \multicolumn{2}{|c|}{ Assoc/Full } & \multicolumn{2}{|c|}{ Open } & \multicolumn{2}{|c|}{ Chair \& Head } & \multicolumn{2}{|c|}{ Others } & \multicolumn{2}{|c|}{ Total } \\
\hline Year & $\mathbf{N}$ & $\%$ & $\mathbf{N}$ & $\%$ & $\mathbf{N}$ & $\%$ & $\mathbf{N}$ & $\%$ & $\mathbf{N}$ & $\%$ & $\mathbf{N}$ & $\%$ & $\mathbf{N}$ & $\%$ & $\mathbf{N}$ & $\%$ & $\mathbf{N}$ & $\%$ \\
\hline \multicolumn{19}{|c|}{ Panel A1. The Overall Finance Hire Market - Private \& Public Universities } \\
\hline 1989 & 47 & $21 \%$ & 2 & $1 \%$ & 73 & $33 \%$ & 5 & $2 \%$ & 8 & $4 \%$ & 73 & $33 \%$ & 14 & $6 \%$ & 0 & $0 \%$ & 222 & $100 \%$ \\
\hline 1990 & 53 & $25 \%$ & 2 & $1 \%$ & 60 & $29 \%$ & 1 & $0 \%$ & 3 & $1 \%$ & 77 & $37 \%$ & 11 & $5 \%$ & 1 & $0 \%$ & 208 & $100 \%$ \\
\hline 1991 & 41 & $28 \%$ & 4 & $3 \%$ & 43 & $30 \%$ & 0 & $0 \%$ & 5 & $3 \%$ & 46 & $32 \%$ & 5 & $3 \%$ & 1 & $1 \%$ & 145 & $100 \%$ \\
\hline 1992 & 45 & $32 \%$ & 1 & $1 \%$ & 37 & $26 \%$ & 1 & $1 \%$ & 5 & $4 \%$ & 47 & $33 \%$ & 5 & $4 \%$ & 1 & $1 \%$ & 142 & $100 \%$ \\
\hline 1993 & 36 & $26 \%$ & 0 & $0 \%$ & 37 & $27 \%$ & 0 & $0 \%$ & 7 & $5 \%$ & 51 & $37 \%$ & 4 & $3 \%$ & 2 & $1 \%$ & 137 & $100 \%$ \\
\hline 1994 & 40 & $30 \%$ & 0 & $0 \%$ & 38 & $28 \%$ & 0 & $0 \%$ & 3 & $2 \%$ & 45 & $33 \%$ & 8 & $6 \%$ & 1 & $1 \%$ & 135 & $100 \%$ \\
\hline 1995 & 42 & $39 \%$ & 0 & $0 \%$ & 32 & $30 \%$ & 0 & $0 \%$ & 1 & $1 \%$ & 26 & $24 \%$ & 6 & $6 \%$ & 0 & $0 \%$ & 107 & $100 \%$ \\
\hline 1996 & 44 & $28 \%$ & 1 & $1 \%$ & 31 & $20 \%$ & 0 & $0 \%$ & 7 & $4 \%$ & 62 & $40 \%$ & 8 & $5 \%$ & 3 & $2 \%$ & 156 & $100 \%$ \\
\hline 1997 & 61 & $38 \%$ & 0 & $0 \%$ & 39 & $24 \%$ & 1 & $1 \%$ & 1 & $1 \%$ & 42 & $26 \%$ & 8 & $5 \%$ & 10 & $6 \%$ & 162 & $100 \%$ \\
\hline 1998 & 57 & $31 \%$ & 4 & $2 \%$ & 62 & $34 \%$ & 0 & $0 \%$ & 3 & $2 \%$ & 40 & $22 \%$ & 12 & $6 \%$ & 7 & $4 \%$ & 185 & $100 \%$ \\
\hline 1999 & 57 & $32 \%$ & 0 & $0 \%$ & 57 & $32 \%$ & 2 & $1 \%$ & 5 & $3 \%$ & 38 & $21 \%$ & 10 & $6 \%$ & 8 & $5 \%$ & 177 & $100 \%$ \\
\hline 2000 & 71 & $31 \%$ & 0 & $0 \%$ & 74 & $32 \%$ & 1 & $0 \%$ & 3 & $1 \%$ & 68 & $29 \%$ & 12 & $5 \%$ & 3 & $1 \%$ & 232 & $100 \%$ \\
\hline 2001 & 58 & $32 \%$ & 0 & $0 \%$ & 63 & $35 \%$ & 3 & $2 \%$ & 3 & $2 \%$ & 47 & $26 \%$ & 5 & $3 \%$ & 0 & $0 \%$ & 179 & $100 \%$ \\
\hline Total & 652 & $30 \%$ & 14 & $1 \%$ & 646 & $30 \%$ & 14 & $1 \%$ & 54 & $2 \%$ & 662 & $30 \%$ & 108 & $5 \%$ & 37 & $2 \%$ & 2187 & $100 \%$ \\
\hline Mean & 50.2 & & 1.1 & & 49.7 & & 1.1 & & 4.2 & & 50.9 & & 8.3 & & 2.8 & & 168.2 & \\
\hline S.D & 10.2 & & 1.5 & & 15.6 & & 1.5 & & 2.2 & & 14.9 & & 3.3 & & 3.3 & & 36.8 & \\
\hline \multicolumn{19}{|c|}{ Panel A2. The Overall Finance Hire Market - Private Universities } \\
\hline 1989 & 13 & $20 \%$ & 1 & $2 \%$ & 23 & $36 \%$ & 3 & $5 \%$ & 6 & $9 \%$ & 13 & $20 \%$ & 5 & $8 \%$ & 0 & $0 \%$ & 64 & $100 \%$ \\
\hline 1990 & 17 & $30 \%$ & 1 & $2 \%$ & 14 & $25 \%$ & 1 & $2 \%$ & 2 & $4 \%$ & 16 & $29 \%$ & 5 & $9 \%$ & 0 & $0 \%$ & 56 & $100 \%$ \\
\hline 1991 & 14 & $39 \%$ & 1 & $3 \%$ & 10 & $28 \%$ & 0 & $0 \%$ & 2 & $6 \%$ & 9 & $25 \%$ & 0 & $0 \%$ & 0 & $0 \%$ & 36 & $100 \%$ \\
\hline 1992 & 18 & $45 \%$ & 1 & $3 \%$ & 10 & $25 \%$ & 0 & $0 \%$ & 1 & $3 \%$ & 9 & $23 \%$ & 1 & $3 \%$ & 0 & $0 \%$ & 40 & $100 \%$ \\
\hline 1993 & 14 & $39 \%$ & 0 & $0 \%$ & 5 & $14 \%$ & 0 & $0 \%$ & 0 & $0 \%$ & 16 & $44 \%$ & 0 & $0 \%$ & 1 & $3 \%$ & 36 & $100 \%$ \\
\hline 1994 & 15 & $38 \%$ & 0 & $0 \%$ & 11 & $28 \%$ & 0 & $0 \%$ & 0 & $0 \%$ & 12 & $31 \%$ & 1 & $3 \%$ & 0 & $0 \%$ & 39 & $100 \%$ \\
\hline 1995 & 10 & $33 \%$ & 0 & $0 \%$ & 12 & $40 \%$ & 0 & $0 \%$ & 0 & $0 \%$ & 7 & $23 \%$ & 1 & $3 \%$ & 0 & $0 \%$ & 30 & $100 \%$ \\
\hline 1996 & 10 & $24 \%$ & 0 & $0 \%$ & 8 & $20 \%$ & 0 & $0 \%$ & 1 & $2 \%$ & 18 & $44 \%$ & 4 & $10 \%$ & 0 & $0 \%$ & 41 & $100 \%$ \\
\hline 1997 & 13 & $33 \%$ & 0 & $0 \%$ & 10 & $26 \%$ & 0 & $0 \%$ & 1 & $3 \%$ & 10 & $26 \%$ & 5 & $13 \%$ & 0 & $0 \%$ & 39 & $100 \%$ \\
\hline 1998 & 12 & $24 \%$ & 0 & $0 \%$ & 20 & $41 \%$ & 0 & $0 \%$ & 0 & $0 \%$ & 12 & $24 \%$ & 3 & $6 \%$ & 2 & $4 \%$ & 49 & $100 \%$ \\
\hline 1999 & 20 & $40 \%$ & 0 & $0 \%$ & 14 & $28 \%$ & 0 & $0 \%$ & 2 & $4 \%$ & 9 & $18 \%$ & 3 & $6 \%$ & 2 & $4 \%$ & 50 & $100 \%$ \\
\hline 2000 & 18 & $32 \%$ & 0 & $0 \%$ & 10 & $18 \%$ & 0 & $0 \%$ & 0 & $0 \%$ & 20 & $35 \%$ & 7 & $12 \%$ & 2 & $4 \%$ & 57 & $100 \%$ \\
\hline 2001 & 11 & $39 \%$ & 0 & $0 \%$ & 6 & $21 \%$ & 0 & $0 \%$ & 1 & $4 \%$ & 10 & $36 \%$ & 0 & $0 \%$ & 0 & $0 \%$ & 28 & $100 \%$ \\
\hline Total & 185 & $33 \%$ & 4 & $1 \%$ & 153 & $27 \%$ & 4 & $1 \%$ & 16 & $3 \%$ & 161 & $28 \%$ & 35 & $6 \%$ & 7 & $1 \%$ & 565 & $100 \%$ \\
\hline Mean & 14.2 & & 0.3 & & 11.8 & & 0.3 & & 1.2 & & 12.4 & & 2.7 & & 0.5 & & 43.5 & \\
\hline S.D & 3.2 & & 0.5 & & 5.1 & & 0.9 & & 1.6 & & 4.0 & & 2.4 & & 0.9 & & 10.9 & \\
\hline \multicolumn{19}{|c|}{ Panel A3. The Overall Finance Hire Market - Public Universities } \\
\hline 1989 & 34 & $22 \%$ & 1 & $1 \%$ & 50 & $32 \%$ & 2 & $1 \%$ & 2 & $1 \%$ & 60 & $38 \%$ & 9 & $6 \%$ & 0 & $0 \%$ & 158 & $100 \%$ \\
\hline 1990 & 36 & $24 \%$ & 1 & $1 \%$ & 46 & $30 \%$ & 0 & $0 \%$ & 1 & $1 \%$ & 61 & $40 \%$ & 6 & $4 \%$ & 1 & $1 \%$ & 152 & $100 \%$ \\
\hline 1991 & 27 & $25 \%$ & 3 & $3 \%$ & 33 & $30 \%$ & 0 & $0 \%$ & 3 & $3 \%$ & 37 & $35 \%$ & 5 & $5 \%$ & 1 & $1 \%$ & 109 & $100 \%$ \\
\hline 1992 & 27 & $26 \%$ & 0 & $0 \%$ & 27 & $26 \%$ & 1 & $1 \%$ & 4 & $4 \%$ & 38 & $37 \%$ & 4 & $4 \%$ & 1 & $1 \%$ & 102 & $100 \%$ \\
\hline 1993 & 22 & $22 \%$ & 0 & $0 \%$ & 32 & $32 \%$ & 0 & $0 \%$ & 7 & $7 \%$ & 35 & $35 \%$ & 4 & $4 \%$ & 1 & $1 \%$ & 101 & $100 \%$ \\
\hline 1994 & 25 & $26 \%$ & 0 & $0 \%$ & 27 & $28 \%$ & 0 & $0 \%$ & 3 & $3 \%$ & 33 & $34 \%$ & 7 & $7 \%$ & 1 & $1 \%$ & 96 & $100 \%$ \\
\hline 1995 & 32 & $42 \%$ & 0 & $0 \%$ & 20 & $26 \%$ & 0 & $0 \%$ & 1 & $1 \%$ & 19 & $25 \%$ & 5 & $6 \%$ & 0 & $0 \%$ & 77 & $100 \%$ \\
\hline 1996 & 34 & $30 \%$ & 1 & $1 \%$ & 23 & $20 \%$ & 0 & $0 \%$ & 6 & $5 \%$ & 44 & $38 \%$ & 4 & $3 \%$ & 3 & $3 \%$ & 115 & $100 \%$ \\
\hline 1997 & 48 & $39 \%$ & 0 & $0 \%$ & 29 & $24 \%$ & 1 & $1 \%$ & 0 & $0 \%$ & 32 & $26 \%$ & 3 & $2 \%$ & 10 & $8 \%$ & 123 & $100 \%$ \\
\hline 1998 & 45 & $33 \%$ & 4 & $3 \%$ & 42 & $31 \%$ & 0 & $0 \%$ & 3 & $2 \%$ & 28 & $21 \%$ & 9 & $7 \%$ & 5 & $4 \%$ & 136 & $100 \%$ \\
\hline 1999 & 37 & $29 \%$ & 0 & $0 \%$ & 43 & $34 \%$ & 2 & $2 \%$ & 3 & $2 \%$ & 29 & $23 \%$ & 7 & $6 \%$ & 6 & $5 \%$ & 127 & $100 \%$ \\
\hline 2000 & 53 & $30 \%$ & 0 & $0 \%$ & 64 & $37 \%$ & 1 & $1 \%$ & 3 & $2 \%$ & 48 & $27 \%$ & 5 & $3 \%$ & 1 & $1 \%$ & 175 & $100 \%$ \\
\hline 2001 & 47 & $31 \%$ & 0 & $0 \%$ & 57 & $38 \%$ & 3 & $2 \%$ & 2 & $1 \%$ & 37 & $25 \%$ & 5 & $3 \%$ & 0 & $0 \%$ & 151 & $100 \%$ \\
\hline Total & 467 & $29 \%$ & 10 & $1 \%$ & 493 & $30 \%$ & 10 & $1 \%$ & 38 & $2 \%$ & 501 & $31 \%$ & 73 & $5 \%$ & 30 & $2 \%$ & 1622 & $100 \%$ \\
\hline Mean & 35.9 & & 0.8 & & 37.9 & & 0.8 & & 2.9 & & 38.5 & & 5.6 & & 2.3 & & 124.8 & \\
\hline S.D & 9.7 & & 1.3 & & 13.6 & & 1.0 & & 1.9 & & 12.1 & & 1.9 & & 3.0 & & 28.5 & \\
\hline
\end{tabular}


Table 1 (Continued)

\begin{tabular}{|c|c|c|c|c|c|c|c|c|c|c|c|c|c|c|c|c|c|c|}
\hline \multicolumn{3}{|c|}{ Assistant } & \multicolumn{2}{|c|}{ Associate } & \multicolumn{2}{|c|}{ Assist/Assoc } & \multicolumn{2}{|c|}{ Full } & \multicolumn{2}{|c|}{ Assoc/Full } & \multicolumn{2}{|c|}{ Open } & \multicolumn{2}{|c|}{ Chair \& Head } & \multicolumn{2}{|c|}{ Others } & \multicolumn{2}{|c|}{ Total } \\
\hline Year & $\mathbf{N}$ & $\%$ & $\mathbf{N}$ & $\%$ & $\mathbf{N}$ & $\%$ & $\mathbf{N}$ & $\%$ & $\mathbf{N}$ & $\%$ & $\mathbf{N}$ & $\%$ & $\mathbf{N}$ & $\%$ & $\mathbf{N}$ & $\%$ & $\mathbf{N}$ & $\%$ \\
\hline \multicolumn{19}{|c|}{ Panel B1. Top 20 Finance Departments - Private \& Public Universities } \\
\hline 1989 & 4 & $100 \%$ & 0 & $0 \%$ & 0 & $0 \%$ & 0 & $0 \%$ & 0 & $0 \%$ & 0 & $0 \%$ & 0 & $0 \%$ & 0 & $0 \%$ & 4 & $100 \%$ \\
\hline 1990 & 4 & $100 \%$ & 0 & $0 \%$ & 0 & $0 \%$ & 0 & $0 \%$ & 0 & $0 \%$ & 0 & $0 \%$ & 0 & $0 \%$ & 0 & $0 \%$ & 4 & $100 \%$ \\
\hline 1991 & 4 & $100 \%$ & 0 & $0 \%$ & 0 & $0 \%$ & 0 & $0 \%$ & 0 & $0 \%$ & 0 & $0 \%$ & 0 & $0 \%$ & 0 & $0 \%$ & 4 & $100 \%$ \\
\hline 1992 & 4 & $100 \%$ & 0 & $0 \%$ & 0 & $0 \%$ & 0 & $0 \%$ & 0 & $0 \%$ & 0 & $0 \%$ & 0 & $0 \%$ & 0 & $0 \%$ & 4 & $100 \%$ \\
\hline 1993 & 4 & $100 \%$ & 0 & $0 \%$ & 0 & $0 \%$ & 0 & $0 \%$ & 0 & $0 \%$ & 0 & $0 \%$ & 0 & $0 \%$ & 0 & $0 \%$ & 4 & $100 \%$ \\
\hline 1994 & 2 & $67 \%$ & 0 & $0 \%$ & 1 & $33 \%$ & 0 & $0 \%$ & 0 & $0 \%$ & 0 & $0 \%$ & 0 & $0 \%$ & 0 & $0 \%$ & 3 & $100 \%$ \\
\hline 1995 & 3 & $100 \%$ & 0 & $0 \%$ & 0 & $0 \%$ & 0 & $0 \%$ & 0 & $0 \%$ & 0 & $0 \%$ & 0 & $0 \%$ & 0 & $0 \%$ & 3 & $100 \%$ \\
\hline 1996 & 1 & $13 \%$ & 0 & $0 \%$ & 1 & $13 \%$ & 0 & $0 \%$ & 0 & $0 \%$ & 6 & $75 \%$ & 0 & $0 \%$ & 0 & $0 \%$ & 8 & $100 \%$ \\
\hline 1997 & 2 & $50 \%$ & 0 & $0 \%$ & 1 & $25 \%$ & 0 & $0 \%$ & 0 & $0 \%$ & 1 & $25 \%$ & 0 & $0 \%$ & 0 & $0 \%$ & 4 & $100 \%$ \\
\hline 1998 & 4 & $80 \%$ & 0 & $0 \%$ & 0 & $0 \%$ & 0 & $0 \%$ & 0 & $0 \%$ & 1 & $20 \%$ & 0 & $0 \%$ & 0 & $0 \%$ & 5 & $100 \%$ \\
\hline 1999 & 2 & $50 \%$ & 0 & $0 \%$ & 1 & $25 \%$ & 0 & $0 \%$ & 0 & $0 \%$ & 1 & $25 \%$ & 0 & $0 \%$ & 0 & $0 \%$ & 4 & $100 \%$ \\
\hline 2000 & 5 & $63 \%$ & 0 & $0 \%$ & 1 & $13 \%$ & 0 & $0 \%$ & 0 & $0 \%$ & 2 & $25 \%$ & 0 & $0 \%$ & 0 & $0 \%$ & 8 & $100 \%$ \\
\hline 2001 & 3 & $60 \%$ & 0 & $0 \%$ & 2 & $40 \%$ & 0 & $0 \%$ & 0 & $0 \%$ & 0 & $0 \%$ & 0 & $0 \%$ & 0 & $0 \%$ & 5 & $100 \%$ \\
\hline Total & 42 & $70 \%$ & 0 & $0 \%$ & 7 & $12 \%$ & 0 & $0 \%$ & 0 & 0\% & 11 & $18 \%$ & 0 & $0 \%$ & 0 & $0 \%$ & 60 & $100 \%$ \\
\hline Mean & 3.2 & & 0 & & 0.5 & & 0 & & 0 & & 0.8 & & 0 & & 0 & & 4.6 & \\
\hline S.D & 1.2 & & 0 & & 0.7 & & 0 & & 0 & & 1.7 & & 0 & & 0 & & 1.6 & \\
\hline \multicolumn{19}{|c|}{ Panel B2. Top 20 Finance Departments - Private Universities } \\
\hline 1989 & 4 & $100 \%$ & 0 & $0 \%$ & 0 & $0 \%$ & 0 & $0 \%$ & 0 & $0 \%$ & 0 & $0 \%$ & 0 & $0 \%$ & 0 & $0 \%$ & 4 & $100 \%$ \\
\hline 1990 & 3 & $100 \%$ & 0 & $0 \%$ & 0 & $0 \%$ & 0 & $0 \%$ & 0 & $0 \%$ & 0 & $0 \%$ & 0 & $0 \%$ & 0 & $0 \%$ & 3 & $100 \%$ \\
\hline 1991 & 3 & $100 \%$ & 0 & $0 \%$ & 0 & $0 \%$ & 0 & $0 \%$ & 0 & $0 \%$ & 0 & $0 \%$ & 0 & $0 \%$ & 0 & $0 \%$ & 3 & $100 \%$ \\
\hline 1992 & 4 & $100 \%$ & 0 & $0 \%$ & 0 & $0 \%$ & 0 & $0 \%$ & 0 & $0 \%$ & 0 & $0 \%$ & 0 & $0 \%$ & 0 & $0 \%$ & 4 & $100 \%$ \\
\hline 1993 & 4 & $100 \%$ & 0 & $0 \%$ & 0 & $0 \%$ & 0 & $0 \%$ & 0 & $0 \%$ & 0 & $0 \%$ & 0 & $0 \%$ & 0 & $0 \%$ & 4 & $100 \%$ \\
\hline 1994 & 2 & $67 \%$ & 0 & $0 \%$ & 1 & $33 \%$ & 0 & $0 \%$ & 0 & $0 \%$ & 0 & $0 \%$ & 0 & $0 \%$ & 0 & $0 \%$ & 3 & $100 \%$ \\
\hline 1995 & 2 & $100 \%$ & 0 & $0 \%$ & 0 & $0 \%$ & 0 & $0 \%$ & 0 & $0 \%$ & 0 & $0 \%$ & 0 & $0 \%$ & 0 & $0 \%$ & 2 & $100 \%$ \\
\hline 1996 & 1 & $20 \%$ & 0 & $0 \%$ & 1 & $20 \%$ & 0 & $0 \%$ & 0 & $0 \%$ & 3 & $60 \%$ & 0 & $0 \%$ & 0 & $0 \%$ & 5 & $100 \%$ \\
\hline 1997 & 2 & $67 \%$ & 0 & $0 \%$ & 1 & $33 \%$ & 0 & $0 \%$ & 0 & $0 \%$ & 0 & $0 \%$ & 0 & $0 \%$ & 0 & $0 \%$ & 3 & $100 \%$ \\
\hline 1998 & 3 & $100 \%$ & 0 & $0 \%$ & 0 & $0 \%$ & 0 & $0 \%$ & 0 & $0 \%$ & 0 & $0 \%$ & 0 & $0 \%$ & 0 & $0 \%$ & 3 & $100 \%$ \\
\hline 1999 & 2 & $67 \%$ & 0 & $0 \%$ & 1 & $33 \%$ & 0 & $0 \%$ & 0 & $0 \%$ & 0 & $0 \%$ & 0 & $0 \%$ & 0 & $0 \%$ & 3 & $100 \%$ \\
\hline 2000 & 4 & $80 \%$ & 0 & $0 \%$ & 1 & $20 \%$ & 0 & $0 \%$ & 0 & $0 \%$ & 0 & $0 \%$ & 0 & $0 \%$ & 0 & $0 \%$ & 5 & $100 \%$ \\
\hline 2001 & 3 & $100 \%$ & 0 & $0 \%$ & 0 & $0 \%$ & 0 & $0 \%$ & 0 & $0 \%$ & 0 & $0 \%$ & 0 & $0 \%$ & 0 & $0 \%$ & 3 & $100 \%$ \\
\hline Total & 37 & $82 \%$ & 0 & $0 \%$ & 5 & $11 \%$ & 0 & $0 \%$ & 0 & $0 \%$ & 3 & $7 \%$ & 0 & $\mathbf{0 \%}$ & 0 & $0 \%$ & 45 & $100 \%$ \\
\hline Mean & 2.8 & & 0.0 & & 0.4 & & 0.0 & & 0.0 & & 0.2 & & 0.0 & & 0.0 & & 3.5 & \\
\hline S.D & 1.0 & & 0.0 & & 0.5 & & 0.0 & & 0.0 & & 0.8 & & 0.0 & & 0.0 & & 0.9 & \\
\hline \multicolumn{19}{|c|}{ Panel B3. Top 20 Finance Departments - Public Universities } \\
\hline 1989 & 0 & $0 \%$ & 0 & $0 \%$ & 0 & $0 \%$ & 0 & $0 \%$ & 0 & $0 \%$ & 0 & $0 \%$ & 0 & $0 \%$ & 0 & $0 \%$ & 0 & $0 \%$ \\
\hline 1990 & 1 & $100 \%$ & 0 & $0 \%$ & 0 & $0 \%$ & 0 & $0 \%$ & 0 & $0 \%$ & 0 & $0 \%$ & 0 & $0 \%$ & 0 & $0 \%$ & 1 & $100 \%$ \\
\hline 1991 & 1 & $100 \%$ & 0 & $0 \%$ & 0 & $0 \%$ & 0 & $0 \%$ & 0 & $0 \%$ & 0 & $0 \%$ & 0 & $0 \%$ & 0 & $0 \%$ & 1 & $100 \%$ \\
\hline 1992 & 0 & $0 \%$ & 0 & $0 \%$ & 0 & $0 \%$ & 0 & $0 \%$ & 0 & $0 \%$ & 0 & $0 \%$ & 0 & $0 \%$ & 0 & $0 \%$ & 0 & $0 \%$ \\
\hline 1993 & 0 & $0 \%$ & 0 & $0 \%$ & 0 & $0 \%$ & 0 & $0 \%$ & 0 & $0 \%$ & 0 & $0 \%$ & 0 & $0 \%$ & 0 & $0 \%$ & 0 & $0 \%$ \\
\hline 1994 & 0 & $0 \%$ & 0 & $0 \%$ & 0 & $0 \%$ & 0 & $0 \%$ & 0 & $0 \%$ & 0 & $0 \%$ & 0 & $0 \%$ & 0 & $0 \%$ & 0 & $0 \%$ \\
\hline 1995 & 1 & $100 \%$ & 0 & $0 \%$ & 0 & $0 \%$ & 0 & $0 \%$ & 0 & $0 \%$ & 0 & $0 \%$ & 0 & $0 \%$ & 0 & $0 \%$ & 1 & $100 \%$ \\
\hline 1996 & 0 & $0 \%$ & 0 & $0 \%$ & 0 & $0 \%$ & 0 & $0 \%$ & 0 & $0 \%$ & 3 & $100 \%$ & 0 & $0 \%$ & 0 & $0 \%$ & 3 & $100 \%$ \\
\hline 1997 & 0 & $0 \%$ & 0 & $0 \%$ & 0 & $0 \%$ & 0 & $0 \%$ & 0 & $0 \%$ & 1 & $100 \%$ & 0 & $0 \%$ & 0 & $0 \%$ & 1 & $100 \%$ \\
\hline 1998 & 1 & $50 \%$ & 0 & $0 \%$ & 0 & $0 \%$ & 0 & $0 \%$ & 0 & $0 \%$ & 1 & $50 \%$ & 0 & $0 \%$ & 0 & $0 \%$ & 2 & $100 \%$ \\
\hline 1999 & 0 & $0 \%$ & 0 & $0 \%$ & 0 & $0 \%$ & 0 & $0 \%$ & 0 & $0 \%$ & 1 & $100 \%$ & 0 & $0 \%$ & 0 & $0 \%$ & 1 & $100 \%$ \\
\hline 2000 & 1 & $33 \%$ & 0 & $0 \%$ & 0 & $0 \%$ & 0 & $0 \%$ & 0 & $0 \%$ & 2 & $67 \%$ & 0 & $0 \%$ & 0 & $0 \%$ & 3 & $100 \%$ \\
\hline 2001 & 0 & $0 \%$ & 0 & $0 \%$ & 2 & $100 \%$ & 0 & $0 \%$ & 0 & $0 \%$ & 0 & $0 \%$ & 0 & $0 \%$ & 0 & $0 \%$ & 2 & $100 \%$ \\
\hline Total & 5 & $33 \%$ & 0 & $0 \%$ & 2 & $13 \%$ & 0 & $0 \%$ & 0 & $0 \%$ & 8 & $53 \%$ & 0 & $0 \%$ & 0 & $0 \%$ & 15 & $100 \%$ \\
\hline Mean & 0.4 & & 0.0 & & 0.2 & & 0.0 & & 0.0 & & 0.6 & & 0.0 & & 0.0 & & 1.2 & \\
\hline S.D & 0.5 & & 0.0 & & 0.6 & & 0.0 & & 0.0 & & 1.0 & & 0.0 & & 0.0 & & 1.1 & \\
\hline
\end{tabular}

fessors only are also not actively sought after by this group of institutions, where only one opening is demanded over the whole 13-year sample period (specifically in 1989). The total number of chairs and head positions available averages less than one opening a year, which is comparable to the Top 20 Finance Departments where there are no openings at all. The highest number of total positions in the Top 21-50 group is 24 in 1992 and 2001 and the lowest is 12 in 1995. In an average year, there are only two positions demanded by the private schools (Table 1, Panel C2), whereas, 16 are demanded by the public schools (Table 1, Panel C3).

\subsubsection{Other finance departments}

As reported in Panel D1 of Table 1, the total number of positions demanded by the Other Finance Departments declined from 204 positions in 1989 to a low of 92 positions in 1995, 
Table 1 (Continued)

\begin{tabular}{|c|c|c|c|c|c|c|c|c|c|c|c|c|c|c|c|c|c|c|}
\hline \multicolumn{3}{|c|}{ Assistant } & \multicolumn{2}{|c|}{ Associate } & \multicolumn{2}{|c|}{ Assist/Assoc } & \multicolumn{2}{|c|}{ Full } & \multicolumn{2}{|c|}{ Assoc/Full } & \multicolumn{2}{|c|}{ Open } & \multicolumn{2}{|c|}{ Chair \& Head } & \multicolumn{2}{|c|}{ Others } & \multicolumn{2}{|c|}{ Total } \\
\hline Year & $\mathbf{N}$ & $\%$ & $\mathbf{N}$ & $\%$ & $\mathbf{N}$ & $\%$ & $\mathbf{N}$ & $\%$ & $\mathbf{N}$ & $\%$ & $\mathbf{N}$ & $\%$ & $\mathbf{N}$ & $\%$ & $\mathbf{N}$ & $\%$ & $\mathbf{N}$ & $\%$ \\
\hline \multicolumn{19}{|c|}{ Panel C1. Top 21-50 Finance Departments - Private \& Public Universities } \\
\hline 1989 & 2 & $14 \%$ & 0 & $0 \%$ & 4 & $29 \%$ & 1 & $7 \%$ & 1 & $7 \%$ & 5 & $36 \%$ & 1 & $7 \%$ & 0 & $0 \%$ & 14 & $100 \%$ \\
\hline 1990 & 2 & $13 \%$ & 1 & $7 \%$ & 4 & $27 \%$ & 0 & $0 \%$ & 0 & $0 \%$ & 7 & $47 \%$ & 1 & $7 \%$ & 0 & $0 \%$ & 15 & $100 \%$ \\
\hline 1991 & 6 & $43 \%$ & 0 & $0 \%$ & 5 & $36 \%$ & 0 & $0 \%$ & 3 & $21 \%$ & 0 & $0 \%$ & 0 & $0 \%$ & 0 & $0 \%$ & 14 & $100 \%$ \\
\hline 1992 & 10 & $42 \%$ & 0 & $0 \%$ & 4 & $17 \%$ & 0 & $0 \%$ & 0 & $0 \%$ & 9 & $38 \%$ & 1 & $4 \%$ & 0 & $0 \%$ & 24 & $100 \%$ \\
\hline 1993 & 7 & $33 \%$ & 0 & $0 \%$ & 3 & $14 \%$ & 0 & $0 \%$ & 1 & $5 \%$ & 9 & $43 \%$ & 0 & $0 \%$ & 1 & $5 \%$ & 21 & $100 \%$ \\
\hline 1994 & 7 & $32 \%$ & 0 & $0 \%$ & 3 & $14 \%$ & 0 & $0 \%$ & 1 & $5 \%$ & 11 & $50 \%$ & 0 & $0 \%$ & 0 & $0 \%$ & 22 & $100 \%$ \\
\hline 1995 & 6 & $50 \%$ & 0 & $0 \%$ & 1 & $8 \%$ & 0 & $0 \%$ & 0 & $0 \%$ & 3 & $25 \%$ & 2 & $17 \%$ & 0 & $0 \%$ & 12 & $100 \%$ \\
\hline 1996 & 7 & $47 \%$ & 0 & $0 \%$ & 3 & $20 \%$ & 0 & $0 \%$ & 0 & $0 \%$ & 5 & $33 \%$ & 0 & $0 \%$ & 0 & $0 \%$ & 15 & $100 \%$ \\
\hline 1997 & 3 & $23 \%$ & 0 & $0 \%$ & 4 & $31 \%$ & 0 & $0 \%$ & 0 & $0 \%$ & 6 & $46 \%$ & 0 & $0 \%$ & 0 & $0 \%$ & 13 & $100 \%$ \\
\hline 1998 & 6 & $30 \%$ & 0 & $0 \%$ & 3 & $15 \%$ & 0 & $0 \%$ & 0 & $0 \%$ & 9 & $45 \%$ & 0 & $0 \%$ & 2 & $10 \%$ & 20 & $100 \%$ \\
\hline 1999 & 7 & $44 \%$ & 0 & $0 \%$ & 2 & $13 \%$ & 0 & $0 \%$ & 0 & $0 \%$ & 6 & $38 \%$ & 1 & $6 \%$ & 0 & $0 \%$ & 16 & $100 \%$ \\
\hline 2000 & 6 & $30 \%$ & 0 & $0 \%$ & 5 & $25 \%$ & 0 & $0 \%$ & 0 & $0 \%$ & 8 & $40 \%$ & 1 & $5 \%$ & 0 & $0 \%$ & 20 & $100 \%$ \\
\hline 2001 & 10 & $42 \%$ & 0 & $0 \%$ & 4 & $17 \%$ & 0 & $0 \%$ & 1 & $4 \%$ & 9 & $38 \%$ & 0 & $0 \%$ & 0 & $0 \%$ & 24 & $100 \%$ \\
\hline Total & 79 & $34 \%$ & 1 & $0 \%$ & 45 & $20 \%$ & 1 & $0 \%$ & 7 & $3 \%$ & 87 & $38 \%$ & 7 & $3 \%$ & 3 & $1 \%$ & 230 & $100 \%$ \\
\hline Mean & 6.1 & & 0.1 & & 3.5 & & 0.1 & & 0.5 & & 6.7 & & 0.5 & & 0.2 & & 17.7 & \\
\hline S.D & 2.5 & & 0.3 & & 1.1 & & 0.3 & & 0.9 & & 3.0 & & 0.7 & & 0.6 & & 4.3 & \\
\hline \multicolumn{19}{|c|}{ Panel C2. Top 21-50 Finance Departments - Private Universities } \\
\hline 1989 & 0 & $0 \%$ & 0 & $0 \%$ & 1 & $33 \%$ & 0 & $0 \%$ & 1 & $33 \%$ & 1 & $33 \%$ & 0 & $0 \%$ & 0 & $0 \%$ & 3 & $100 \%$ \\
\hline 1990 & 0 & $0 \%$ & 0 & $0 \%$ & 0 & $0 \%$ & 0 & $0 \%$ & 0 & $0 \%$ & 1 & $50 \%$ & 1 & $50 \%$ & 0 & $0 \%$ & 2 & $100 \%$ \\
\hline 1991 & 0 & $0 \%$ & 0 & $0 \%$ & 0 & $0 \%$ & 0 & $0 \%$ & 0 & $0 \%$ & 0 & $0 \%$ & 0 & $0 \%$ & 0 & $0 \%$ & 0 & $0 \%$ \\
\hline 1992 & 5 & $83 \%$ & 0 & $0 \%$ & 1 & $17 \%$ & 0 & $0 \%$ & 0 & $0 \%$ & 0 & $0 \%$ & 0 & $0 \%$ & 0 & $0 \%$ & 6 & $100 \%$ \\
\hline 1993 & 0 & $0 \%$ & 0 & $0 \%$ & 2 & $100 \%$ & 0 & $0 \%$ & 0 & $0 \%$ & 0 & $0 \%$ & 0 & $0 \%$ & 0 & $0 \%$ & 2 & $100 \%$ \\
\hline 1994 & 3 & $75 \%$ & 0 & $0 \%$ & 0 & $0 \%$ & 0 & $0 \%$ & 0 & $0 \%$ & 1 & $25 \%$ & 0 & $0 \%$ & 0 & $0 \%$ & 4 & $100 \%$ \\
\hline 1995 & 1 & $100 \%$ & 0 & $0 \%$ & 0 & $0 \%$ & 0 & $0 \%$ & 0 & $0 \%$ & 0 & $0 \%$ & 0 & $0 \%$ & 0 & $0 \%$ & 1 & $100 \%$ \\
\hline 1996 & 2 & $100 \%$ & 0 & $0 \%$ & 0 & $0 \%$ & 0 & $0 \%$ & 0 & $0 \%$ & 0 & $0 \%$ & 0 & $0 \%$ & 0 & $0 \%$ & 2 & $100 \%$ \\
\hline 1997 & 0 & $0 \%$ & 0 & $0 \%$ & 0 & $0 \%$ & 0 & $0 \%$ & 0 & $0 \%$ & 1 & $100 \%$ & 0 & $0 \%$ & 0 & $0 \%$ & 1 & $100 \%$ \\
\hline 1998 & 0 & $0 \%$ & 0 & $0 \%$ & 0 & $0 \%$ & 0 & $0 \%$ & 0 & $0 \%$ & 1 & $100 \%$ & 0 & $0 \%$ & 0 & $0 \%$ & 1 & $100 \%$ \\
\hline 1999 & 1 & $100 \%$ & 0 & $0 \%$ & 0 & $0 \%$ & 0 & $0 \%$ & 0 & $0 \%$ & 0 & $0 \%$ & 0 & $0 \%$ & 0 & $0 \%$ & 1 & $100 \%$ \\
\hline 2000 & 0 & $0 \%$ & 0 & $0 \%$ & 0 & $0 \%$ & 0 & $0 \%$ & 0 & $0 \%$ & 2 & $100 \%$ & 0 & $0 \%$ & 0 & $0 \%$ & 2 & $100 \%$ \\
\hline 2001 & 0 & $0 \%$ & 0 & $0 \%$ & 0 & $0 \%$ & 0 & $0 \%$ & 0 & $0 \%$ & 0 & $0 \%$ & 0 & $0 \%$ & 0 & $0 \%$ & 0 & $0 \%$ \\
\hline Total & 12 & $48 \%$ & 0 & $0 \%$ & 4 & $16 \%$ & 0 & $0 \%$ & 1 & $4 \%$ & 7 & $28 \%$ & 1 & $4 \%$ & 0 & $0 \%$ & 25 & $100 \%$ \\
\hline Mean & 0.9 & & 0.0 & & 0.3 & & 0.0 & & 0.1 & & 0.5 & & 0.1 & & 0.0 & & 1.9 & \\
\hline S.D & 1.6 & & 0.0 & & 0.6 & & 0.0 & & 0.3 & & 0.7 & & 0.3 & & 0.0 & & 1.7 & \\
\hline \multicolumn{19}{|c|}{ Panel C3. Top 21-50 Finance Departments - Public Universities } \\
\hline 1989 & 2 & $18 \%$ & 0 & $0 \%$ & 3 & $27 \%$ & 1 & 9 & 0 & $0 \%$ & 4 & $36 \%$ & 1 & $9 \%$ & 0 & $0 \%$ & 11 & $100 \%$ \\
\hline 1990 & 2 & $15 \%$ & 1 & $8 \%$ & 4 & $31 \%$ & 0 & $0 \%$ & 0 & $0 \%$ & 6 & $46 \%$ & 0 & $0 \%$ & 0 & $0 \%$ & 13 & $100 \%$ \\
\hline 1991 & 6 & $43 \%$ & 0 & $0 \%$ & 5 & $36 \%$ & 0 & $0 \%$ & 3 & $21 \%$ & 0 & $0 \%$ & 0 & $0 \%$ & 0 & $0 \%$ & 14 & $100 \%$ \\
\hline 1992 & 5 & $28 \%$ & 0 & $0 \%$ & 3 & $17 \%$ & 0 & $0 \%$ & 0 & $0 \%$ & 9 & $50 \%$ & 1 & $6 \%$ & 0 & $0 \%$ & 18 & $100 \%$ \\
\hline 1993 & 7 & $37 \%$ & 0 & $0 \%$ & 1 & $5 \%$ & 0 & $0 \%$ & 1 & $5 \%$ & 9 & $47 \%$ & 0 & $0 \%$ & 1 & $5 \%$ & 19 & $100 \%$ \\
\hline 1994 & 4 & $22 \%$ & 0 & $0 \%$ & 3 & $17 \%$ & 0 & $0 \%$ & 1 & $6 \%$ & 10 & $56 \%$ & 0 & $0 \%$ & 0 & $0 \%$ & 18 & $100 \%$ \\
\hline 1995 & 5 & $45 \%$ & 0 & $0 \%$ & 1 & $9 \%$ & 0 & $0 \%$ & 0 & $0 \%$ & 3 & $27 \%$ & 2 & $18 \%$ & 0 & $0 \%$ & 11 & $100 \%$ \\
\hline 1996 & 5 & $38 \%$ & 0 & $0 \%$ & 3 & $23 \%$ & 0 & $0 \%$ & 0 & $0 \%$ & 5 & $38 \%$ & 0 & $0 \%$ & 0 & $0 \%$ & 13 & $100 \%$ \\
\hline 1997 & 3 & $25 \%$ & 0 & $0 \%$ & 4 & $33 \%$ & 0 & $0 \%$ & 0 & $0 \%$ & 5 & $42 \%$ & 0 & $0 \%$ & 0 & $0 \%$ & 12 & $100 \%$ \\
\hline 1998 & 6 & $32 \%$ & 0 & $0 \%$ & 3 & $16 \%$ & 0 & $0 \%$ & 0 & $0 \%$ & 8 & $42 \%$ & 0 & $0 \%$ & 2 & $11 \%$ & 19 & $100 \%$ \\
\hline 1999 & 6 & $40 \%$ & 0 & $0 \%$ & 2 & $13 \%$ & 0 & $0 \%$ & 0 & $0 \%$ & 6 & $40 \%$ & 1 & $7 \%$ & 0 & $0 \%$ & 15 & $100 \%$ \\
\hline 2000 & 6 & $33 \%$ & 0 & $0 \%$ & 5 & $28 \%$ & 0 & $0 \%$ & 0 & $0 \%$ & 6 & $33 \%$ & 1 & $6 \%$ & 0 & $0 \%$ & 18 & $100 \%$ \\
\hline 2001 & 10 & $42 \%$ & 0 & $0 \%$ & 4 & $17 \%$ & 0 & $0 \%$ & 1 & $4 \%$ & 9 & $38 \%$ & 0 & $0 \%$ & 0 & $0 \%$ & 24 & $100 \%$ \\
\hline Total & 67 & $33 \%$ & 1 & $0 \%$ & 41 & $20 \%$ & 1 & $0 \%$ & 6 & $3 \%$ & 80 & $39 \%$ & 6 & $3 \%$ & 3 & $1 \%$ & 205 & $100 \%$ \\
\hline Mean & 5.2 & & 0.1 & & 3.2 & & 0.1 & & 0.5 & & 6.2 & & 0.5 & & 0.2 & & 15.8 & \\
\hline S.D & 2.2 & & 0.3 & & 1.3 & & 0.3 & & 0.9 & & 2.9 & & 0.7 & & 0.6 & & 3.9 & \\
\hline
\end{tabular}

before picking up in 1996. The demand in 2000 returned to its peak of 204 positions but this number declined to 150 positions in 2001. For associate professors only, the total number of positions available over the 13-year sample period is 13, with the highest in 1991 and 1998 at four positions whereas, for full professors only, it is also 13, with the highest in 1989 at four positions. Finally, there are a hefty total of 101 openings for chair or head of department, which represents 5 percent of the total number of positions advertised over the 13-year sample period. However, the numbers have declined from a high of 13 positions in 1989 to only five positions in 2001. As shown in Table 1, Panel D2 and D3, the entry-level positions accounts for about 90 percent of the total positions demanded.

We see from the results that all three groups of private and public schools demand more entry-level positions than senior positions. This overwhelmingly supports our hypothesis that the demand for assistant professors is greater than associate or full professors. 
Table 1 (Continued)

\begin{tabular}{|c|c|c|c|c|c|c|c|c|c|c|c|c|c|c|c|c|c|c|}
\hline \multicolumn{3}{|c|}{ Assistant } & \multicolumn{2}{|c|}{ Associate } & \multicolumn{2}{|c|}{ Assist/Assoc } & \multicolumn{2}{|c|}{ Full } & \multicolumn{2}{|c|}{ Assoc/Full } & \multicolumn{2}{|c|}{ Open } & \multicolumn{2}{|c|}{ Chair \& Head } & \multicolumn{2}{|c|}{ Others } & \multicolumn{2}{|c|}{ Total } \\
\hline Year & $\mathbf{N}$ & $\%$ & $\mathbf{N}$ & $\%$ & $\mathbf{N}$ & $\%$ & $\mathbf{N}$ & $\%$ & $\mathbf{N}$ & $\%$ & $\mathbf{N}$ & $\%$ & $\mathbf{N}$ & $\%$ & $\mathbf{N}$ & $\%$ & $\mathbf{N}$ & $\%$ \\
\hline \multicolumn{19}{|c|}{ Panel D1. Other Finance Departments - Private \& Public Universities } \\
\hline 1989 & 41 & $20 \%$ & 2 & $1 \%$ & 69 & $34 \%$ & 4 & $2 \%$ & 7 & $3 \%$ & 68 & $33 \%$ & 13 & $6 \%$ & 0 & $0 \%$ & 204 & $100 \%$ \\
\hline 1990 & 47 & $25 \%$ & 1 & $1 \%$ & 56 & $30 \%$ & 1 & $1 \%$ & 3 & $2 \%$ & 70 & $37 \%$ & 10 & $5 \%$ & 1 & $1 \%$ & 189 & $100 \%$ \\
\hline 1991 & 31 & $24 \%$ & 4 & $3 \%$ & 38 & $30 \%$ & 0 & $0 \%$ & 2 & $2 \%$ & 46 & $36 \%$ & 5 & $4 \%$ & 1 & $1 \%$ & 127 & $100 \%$ \\
\hline 1992 & 31 & $27 \%$ & 1 & $1 \%$ & 33 & $29 \%$ & 1 & $1 \%$ & 5 & $4 \%$ & 38 & $33 \%$ & 4 & $4 \%$ & 1 & $1 \%$ & 114 & $100 \%$ \\
\hline 1993 & 25 & $22 \%$ & 0 & $0 \%$ & 34 & $30 \%$ & 0 & $0 \%$ & 6 & $5 \%$ & 42 & $38 \%$ & 4 & $4 \%$ & 1 & $1 \%$ & 112 & $100 \%$ \\
\hline 1994 & 31 & $28 \%$ & 0 & $0 \%$ & 34 & $31 \%$ & 0 & $0 \%$ & 2 & $2 \%$ & 34 & $31 \%$ & 8 & $7 \%$ & 1 & $1 \%$ & 110 & $100 \%$ \\
\hline 1995 & 33 & $36 \%$ & 0 & $0 \%$ & 31 & $34 \%$ & 0 & $0 \%$ & 1 & $1 \%$ & 23 & $25 \%$ & 4 & $4 \%$ & 0 & $0 \%$ & 92 & $100 \%$ \\
\hline 1996 & 36 & $27 \%$ & 1 & $1 \%$ & 27 & $20 \%$ & 0 & $0 \%$ & 7 & $5 \%$ & 51 & $38 \%$ & 8 & $6 \%$ & 3 & $2 \%$ & 133 & $100 \%$ \\
\hline 1997 & 56 & $39 \%$ & 0 & $0 \%$ & 34 & $23 \%$ & 1 & $1 \%$ & 1 & $1 \%$ & 35 & $24 \%$ & 8 & $6 \%$ & 10 & $7 \%$ & 145 & $100 \%$ \\
\hline 1998 & 47 & $29 \%$ & 4 & $3 \%$ & 59 & $37 \%$ & 0 & $0 \%$ & 3 & $2 \%$ & 30 & $19 \%$ & 12 & $8 \%$ & 5 & $3 \%$ & 160 & $100 \%$ \\
\hline 1999 & 48 & $31 \%$ & 0 & $0 \%$ & 54 & $34 \%$ & 2 & $1 \%$ & 5 & $3 \%$ & 31 & $20 \%$ & 9 & $6 \%$ & 8 & $5 \%$ & 157 & $100 \%$ \\
\hline 2000 & 60 & $29 \%$ & 0 & $0 \%$ & 68 & $33 \%$ & 1 & $0 \%$ & 3 & $1 \%$ & 58 & $28 \%$ & 11 & $5 \%$ & 3 & $1 \%$ & 204 & $100 \%$ \\
\hline 2001 & 45 & $30 \%$ & 0 & $0 \%$ & 57 & $38 \%$ & 3 & $2 \%$ & 2 & $1 \%$ & 38 & $25 \%$ & 5 & $3 \%$ & 0 & $0 \%$ & 150 & $100 \%$ \\
\hline Total & 531 & $28 \%$ & 13 & $1 \%$ & 594 & $31 \%$ & 13 & $1 \%$ & 47 & $2 \%$ & 564 & $30 \%$ & 101 & $5 \%$ & 34 & $2 \%$ & 1897 & $100 \%$ \\
\hline Mean & 40.8 & & 1.0 & & 45.7 & & 1.0 & & 3.6 & & 43.4 & & 7.8 & & 2.6 & & 145.9 & \\
\hline S.D & 10.7 & & 1.5 & & 15.0 & & 1.3 & & 2.1 & & 14.6 & & 3.2 & & 3.2 & & 36.3 & \\
\hline \multicolumn{19}{|c|}{ Panel D2. Other Finance Departments - Private Universities } \\
\hline 1989 & 9 & $16 \%$ & 1 & $2 \%$ & 22 & $39 \%$ & 3 & $5 \%$ & 5 & $9 \%$ & 12 & $21 \%$ & 5 & $9 \%$ & 0 & $0 \%$ & 57 & $100 \%$ \\
\hline 1990 & 14 & $27 \%$ & 1 & $2 \%$ & 14 & $27 \%$ & 1 & $2 \%$ & 2 & $4 \%$ & 15 & $29 \%$ & 4 & $8 \%$ & 0 & $0 \%$ & 51 & $100 \%$ \\
\hline 1991 & 11 & $33 \%$ & 1 & $3 \%$ & 10 & $30 \%$ & 0 & $0 \%$ & 2 & $6 \%$ & 9 & $27 \%$ & 0 & $0 \%$ & 0 & $0 \%$ & 33 & $100 \%$ \\
\hline 1992 & 9 & $30 \%$ & 1 & $3 \%$ & 9 & $30 \%$ & 0 & $0 \%$ & 1 & $3 \%$ & 9 & $30 \%$ & 1 & $3 \%$ & 0 & $0 \%$ & 30 & $100 \%$ \\
\hline 1993 & 10 & $33 \%$ & 0 & $0 \%$ & 3 & $10 \%$ & 0 & $0 \%$ & 0 & $0 \%$ & 16 & $53 \%$ & 0 & $0 \%$ & 1 & $3 \%$ & 30 & $100 \%$ \\
\hline 1994 & 10 & $31 \%$ & 0 & $0 \%$ & 10 & $31 \%$ & 0 & $0 \%$ & 0 & $0 \%$ & 11 & $34 \%$ & 1 & $3 \%$ & 0 & $0 \%$ & 32 & $100 \%$ \\
\hline 1995 & 7 & $26 \%$ & 0 & $0 \%$ & 12 & $44 \%$ & 0 & $0 \%$ & 0 & $0 \%$ & 7 & $26 \%$ & 1 & $4 \%$ & 0 & $0 \%$ & 27 & $100 \%$ \\
\hline 1996 & 7 & $21 \%$ & 0 & $0 \%$ & 7 & $21 \%$ & 0 & $0 \%$ & 1 & $3 \%$ & 15 & $44 \%$ & 4 & $12 \%$ & 0 & $0 \%$ & 34 & $100 \%$ \\
\hline 1997 & 11 & $31 \%$ & 0 & $0 \%$ & 9 & $26 \%$ & 0 & $0 \%$ & 1 & $3 \%$ & 9 & $26 \%$ & 5 & $14 \%$ & 0 & $0 \%$ & 35 & $100 \%$ \\
\hline 1998 & 9 & $20 \%$ & 0 & $0 \%$ & 20 & $44 \%$ & 0 & $0 \%$ & 0 & $0 \%$ & 11 & $24 \%$ & 3 & $7 \%$ & 2 & $4 \%$ & 45 & $100 \%$ \\
\hline 1999 & 17 & $37 \%$ & 0 & $0 \%$ & 13 & $28 \%$ & 0 & $0 \%$ & 2 & $4 \%$ & 9 & $20 \%$ & 3 & $7 \%$ & 2 & $4 \%$ & 46 & $100 \%$ \\
\hline 2000 & 14 & $28 \%$ & 0 & $0 \%$ & 9 & $18 \%$ & 0 & $0 \%$ & 0 & $0 \%$ & 18 & $36 \%$ & 7 & $14 \%$ & 2 & $4 \%$ & 50 & $100 \%$ \\
\hline 2001 & 8 & $32 \%$ & 0 & $0 \%$ & 6 & $24 \%$ & 0 & $0 \%$ & 1 & $4 \%$ & 10 & $40 \%$ & 0 & $0 \%$ & 0 & $0 \%$ & 25 & $100 \%$ \\
\hline Total & 136 & $27 \%$ & 4 & $1 \%$ & 144 & $29 \%$ & 4 & $1 \%$ & 15 & $3 \%$ & 151 & $31 \%$ & 34 & $7 \%$ & 7 & $1 \%$ & 495 & $100 \%$ \\
\hline Mean & 10.5 & & 0.3 & & 11.1 & & 0.3 & & 1.2 & & 11.6 & & 2.6 & & 0.5 & & 38.1 & \\
\hline S.D & 3.0 & & 0.5 & & 5.3 & & 0.9 & & 1.4 & & 3.4 & & 2.3 & & 0.9 & & 10.4 & \\
\hline \multicolumn{19}{|c|}{ Panel D3. Other Finance Departments - Public Universities } \\
\hline 1989 & 32 & $22 \%$ & 1 & 1 & 47 & $32 \%$ & 1 & $1 \%$ & 2 & $1 \%$ & 56 & $38 \%$ & 8 & $5 \%$ & 0 & $0 \%$ & 147 & \\
\hline 1990 & 33 & $24 \%$ & 0 & $0 \%$ & 42 & $30 \%$ & 0 & $0 \%$ & 1 & $1 \%$ & 55 & $40 \%$ & 6 & $4 \%$ & 1 & $1 \%$ & 138 & $100 \%$ \\
\hline 1991 & 20 & $21 \%$ & 3 & $3 \%$ & 28 & $30 \%$ & 0 & $0 \%$ & 0 & $0 \%$ & 37 & $39 \%$ & 5 & $5 \%$ & 1 & $1 \%$ & 94 & $100 \%$ \\
\hline 1992 & 22 & $26 \%$ & 0 & $0 \%$ & 24 & $29 \%$ & 1 & $1 \%$ & 4 & $5 \%$ & 29 & $35 \%$ & 3 & $4 \%$ & 1 & $1 \%$ & 84 & $100 \%$ \\
\hline 1993 & 15 & $18 \%$ & 0 & $0 \%$ & 31 & $38 \%$ & 0 & $0 \%$ & 6 & $7 \%$ & 26 & $32 \%$ & 4 & $5 \%$ & 0 & $0 \%$ & 82 & $100 \%$ \\
\hline 1994 & 21 & $27 \%$ & 0 & $0 \%$ & 24 & $31 \%$ & 0 & $0 \%$ & 2 & $3 \%$ & 23 & $29 \%$ & 7 & $9 \%$ & 1 & $1 \%$ & 78 & $100 \%$ \\
\hline 1995 & 26 & $40 \%$ & 0 & $0 \%$ & 19 & $29 \%$ & 0 & $0 \%$ & 1 & $2 \%$ & 16 & $25 \%$ & 3 & $5 \%$ & 0 & $0 \%$ & 65 & $100 \%$ \\
\hline 1996 & 29 & $29 \%$ & 1 & $1 \%$ & 20 & $20 \%$ & 0 & $0 \%$ & 6 & $6 \%$ & 36 & $36 \%$ & 4 & $4 \%$ & 3 & $3 \%$ & 99 & $100 \%$ \\
\hline 1997 & 45 & $41 \%$ & 0 & $0 \%$ & 24 & $22 \%$ & 1 & $1 \%$ & 0 & $0 \%$ & 26 & $24 \%$ & 3 & $3 \%$ & 10 & $9 \%$ & 110 & $100 \%$ \\
\hline 1998 & 38 & $33 \%$ & 4 & $3 \%$ & 39 & $34 \%$ & 0 & $0 \%$ & 3 & $3 \%$ & 19 & $17 \%$ & 9 & $8 \%$ & 3 & $3 \%$ & 115 & $100 \%$ \\
\hline 1999 & 31 & $28 \%$ & 0 & $0 \%$ & 41 & $37 \%$ & 2 & $2 \%$ & 3 & $3 \%$ & 22 & $20 \%$ & 6 & $5 \%$ & 6 & $5 \%$ & 111 & $100 \%$ \\
\hline 2000 & 46 & $30 \%$ & 0 & $0 \%$ & 59 & $38 \%$ & 1 & $1 \%$ & 3 & $2 \%$ & 40 & $26 \%$ & 4 & $3 \%$ & 1 & $1 \%$ & 154 & $100 \%$ \\
\hline 2001 & 37 & $30 \%$ & 0 & $0 \%$ & 51 & $41 \%$ & 3 & $2 \%$ & 1 & $1 \%$ & 28 & $22 \%$ & 5 & $4 \%$ & 0 & $0 \%$ & 125 & $100 \%$ \\
\hline Total & 395 & $28 \%$ & 9 & $1 \%$ & 449 & $32 \%$ & 9 & $1 \%$ & 32 & $2 \%$ & 413 & $29 \%$ & 67 & $5 \%$ & 27 & $2 \%$ & 1402 & $100 \%$ \\
\hline Mean & 30.4 & & 0.7 & & 34.5 & & 0.7 & & 2.5 & & 31.8 & & 5.2 & & 2.1 & & 107.8 & \\
\hline S.D & 9.5 & & 1.3 & & 12.9 & & 0.9 & & 2.0 & & 12.6 & & 2.0 & & 2.9 & & 27.6 & \\
\hline
\end{tabular}

\subsubsection{Comparisons across three groups of schools}

As shown in Table 1, Panel E, the demand for positions differs significantly at the 1 percent level between Top 20 and Other Finance Department and between Top 21-50 and Other Finance Department. Among private universities, the distribution for finance openings for assistant, associate, assistant/associate, associate/full, open, and chair ranks differ significantly among the three groups of schools. The results show that there is a significant difference at the 1 percent level among the three groups of schools for each type of positions except for full positions. The Tukey's multiple comparison results show that there is significant difference between the Top 20 and Other groups of schools as well as between the Top 21-50 and Other groups of schools in the demand for the various ranks of professors. Within the public universities, the results reveal that openings for all ranks with the exception of associate professors, differ at the 1 percent level. The multiple-comparison 
Table 1 (Continued)

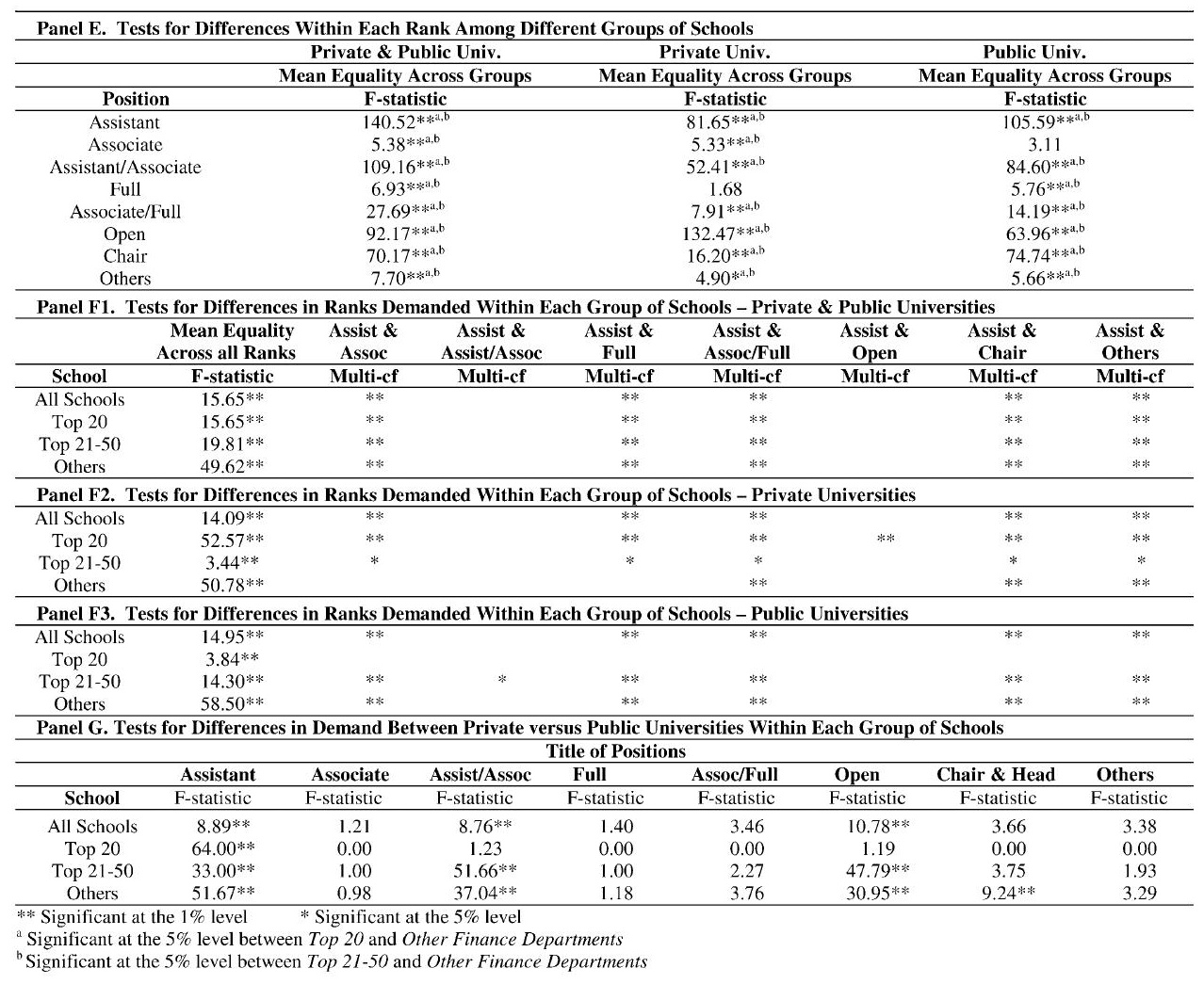

test shows significant difference between the Top 20 and Other groups of schools as well as between the Top 21-50 and Other groups of schools.

The results for Table 1, Panel F1, F2 and F3 reveal significant differences in the proportion of faculty opening among various ranks across the three groups of finance departments. This finding is significant at the 1 percent level across all three categories and types of schools. In particular, the Tukey's multiple comparison results for both private schools and public schools (Table 1, Panel F2 and F3) show significant difference among the assistant and associate, assistant and full, assistant and associate/full, assistant and chair, and assistant and others across the three groups of schools. However, there seems to be no difference between the assistant and assistant/associate and between the assistant and open ranks that are demanded across the three categories of schools. The Tukey's multiple comparison results are similar for that of both the private and public universities combined (Table 1, Panel F1).

Table 1, Panel G, shows that there is significant difference between the private and public universities' demand for the various ranks of professors. In particular, there are differences in their demand for the assistant, assistant/associate rank and in their demand for the open rank. Panel A2 and A3 show that, over the 13-year-period, only 185 as- 
sistant professors are demanded by the private universities, whereas 467 assistant professors are demanded by the public universities. Private universities demanded 153 assistant/associate positions, while public universities demanded 493 similar positions. In contrast, private universities have a total of 161 open positions, whereas public universities have 501.

There are significant differences among the three groups of schools in terms of their demand for the various positions of finance professors. Even within each group of schools, there are significant differences in the positions demanded. Lastly, there is a significant difference between the private and public schools' demand for the various ranks of professors. Despite these differences, more entry-level finance professors are demanded in all three groups of both private and public universities.

\subsection{Degree requirements}

Table 2, Panel A1, reveals a majority of 60 percent of the hiring institutions that require candidates with at least a Ph.D. The demand for Ph.D.s only was particularly high at 76 percent in 1994 and at 74 percent in 1993. It appears that there was an oversupply of new Ph.D. candidates during these 2 years. In general, both private and public schools (Table 2, Panel A2 and A3) prefer candidates who have completed their doctorate degree.

Similar trends of hiring Ph.D. graduates are also noticed in the Top 20 Finance Departments (Table 2, Panel B1, B2 and B3) where an average of at least 60 percent of the openings during the 13-year-period requires an earned Ph.D. In 1994, the percentage of openings requiring the Ph.D. degree hit a low of around 33 percent among private schools in the Top 20 Finance Departments. This could be due to a smaller supply of job candidates in that year. In all years, with the exception of 1997, the Top 21-50 group recorded at least 50 percent of the positions requiring a Ph.D. degree. Hence, it is clear that both the private and public institutions in this group also require their professors to be equipped with at least a Ph.D. degree to be considered for a job offer.

Similarly, in Panel D1 of Table 2, we note that there is a peak in demand for graduates with an earned Ph.D. in 1994 (78 percent) and 1993 (73 percent) in the Other group. However, this requirement appears to be relaxed in 1997, where only 45 percent of the positions required an earned $\mathrm{Ph}$.D. Such a phenomenon seems to be consistent with the tightening of the finance doctoral labor supply in the late 1990s.

The results in Table 2, Panel E, show that the demand for Ph.D.s versus ABDs differs significantly at the 5 percent level for the Top 20 Finance Departments, and 1 percent for the Top 21-50 and Other Finance Departments. Overall, all groups of private and public schools prefer candidates who have obtained their doctorate degree at the time of application rather than near completion. This is in line with our hypothesis that there is a preference for graduates with an earned Ph.D. than those who are ABDs. Table 2 also reveals that there is a significant difference at the 1 percent level for the Top 20 and Other groups of private universities and at the 5 percent significance for the Top 21-50 group in their criteria of candidates' degree requirements. As for the public universities, the candidates' degree requirements also differ for both the Top 21-50 and Other groups. 


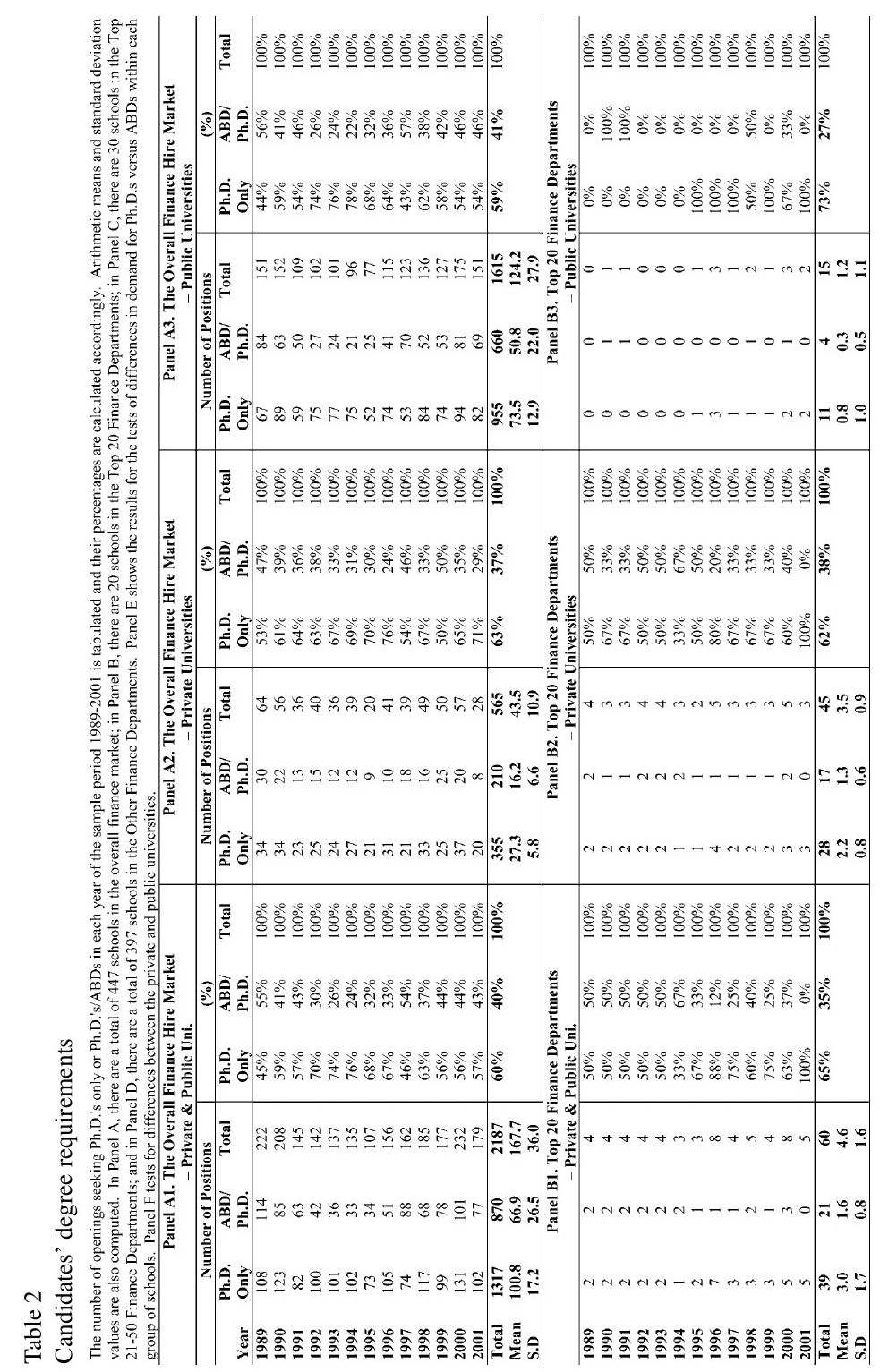




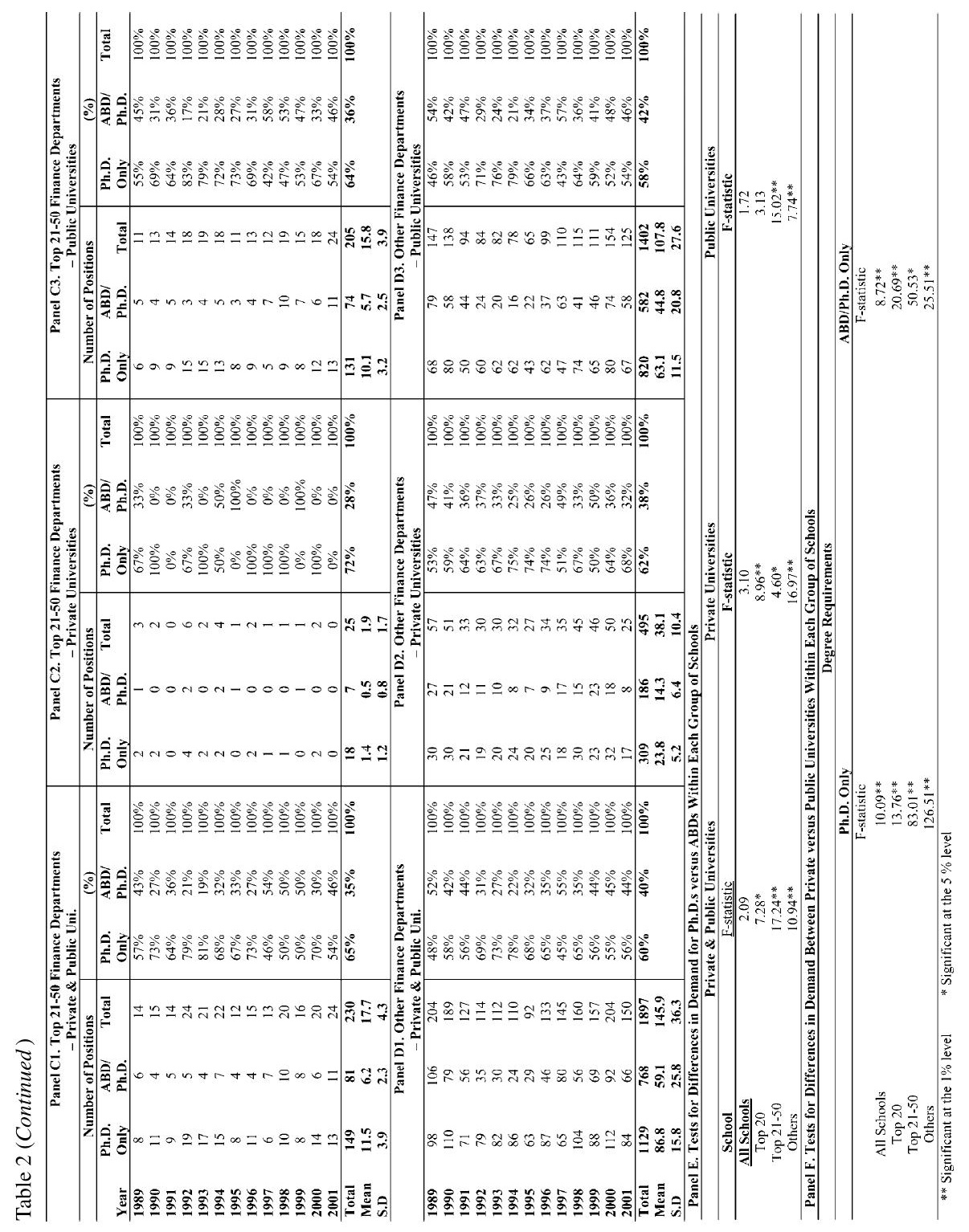


Table 2, Panel F, shows that across all groups of schools, there is a significant difference among the private and public universities' demand for candidates' degree requirements. Table 2, Panel A2 and A3 show that the total demand for Ph.D.s by the private universities is 355 , whereas the total demand for Ph.D.s by the public universities is 955 in the overall finance hire market.

There is a significant difference in the demand for Ph.D. holders and ABD holders within the three groups of schools and between private and public universities' degree requirements for candidates. However, all groups of private and public universities have a preference for candidates who have completed their doctorate.

\subsection{Type of contracts offered}

Out of the total openings in our sample period, it is observed in Table 3, Panel A1, that 52 percent of them promise tenure-track contracts. However, this percentage varies from year to year, hitting a low of 38 percent in 1992 and a high of 68 percent in 1999. There is no clear trend for the types of contracts offered for both the private and public institutions (Table 3, Panel A2 and A3). Similarly, the Top 20 Finance Departments (Table 3, Panel $\mathrm{B} 1, \mathrm{~B} 2$ and B3) show that there is no clear trend for the in the type of contract offered. However, we can see that the percentage of tenure-track contracts offered is mostly not above 60 percent. In much of the sample period, tenure-track positions available in the Top 20 Finance Departments are indeed not the norm..$^{5}$ As the figures in this category have largely fluctuated, we cannot conclude that tenure-tracked positions are on a decline over time, as they have been fairly consistent.

Among the Top 21-50 Finance Departments (Table 3, Panel C1), the mean demand for tenure-track positions is 10 , whereas, the mean demand for the unspecified positions is eight. In Panel C2 and C3, we note that private schools advertised for fewer tenure-track positions (36 percent) than public schools (59 percent). As for the Other Finance Departments, the number of tenure-track positions available is highest at 132 (65 percent) in 2000 and the lowest at 40 (35 percent) in 1992 (Table 3, Panel D1). The number of tenure-track positions offered bottomed out in 1992 but experienced an upward trend till 2000 before falling in 2001. Out of a total number of 1897 positions advertised by this group of schools over the 13-year sample period, 989 (52 percent) are tenure-tracked.

There appears to be no definite trend in the types of contract offered by the universities. We are therefore unable to conclude that the availability of tenure-tracked finance positions is less than non tenure-tracked ones. In fact, in the more recent years, the number of tenure-tracked positions being offered by public universities has been increasing. Overall, the results (Table 3, Panel E1, E2 and E3) show no definitive trend for the type of positions advertised, but it does seem that tenure-track ones are slowly on the rise in recent years. Table 3, Panel F shows significant differences in the types of positions advertised for by the private and the public universities. Table 3, Panel A2 and A3 show that private universities in the overall finance hire market advertised for 299 tenure-track positions whereas public universities advertised for 849 tenure-track positions.

\footnotetext{
${ }^{5}$ It is certainly possible that a number of the unspecified positions are actually tenure-tracked ones.
} 


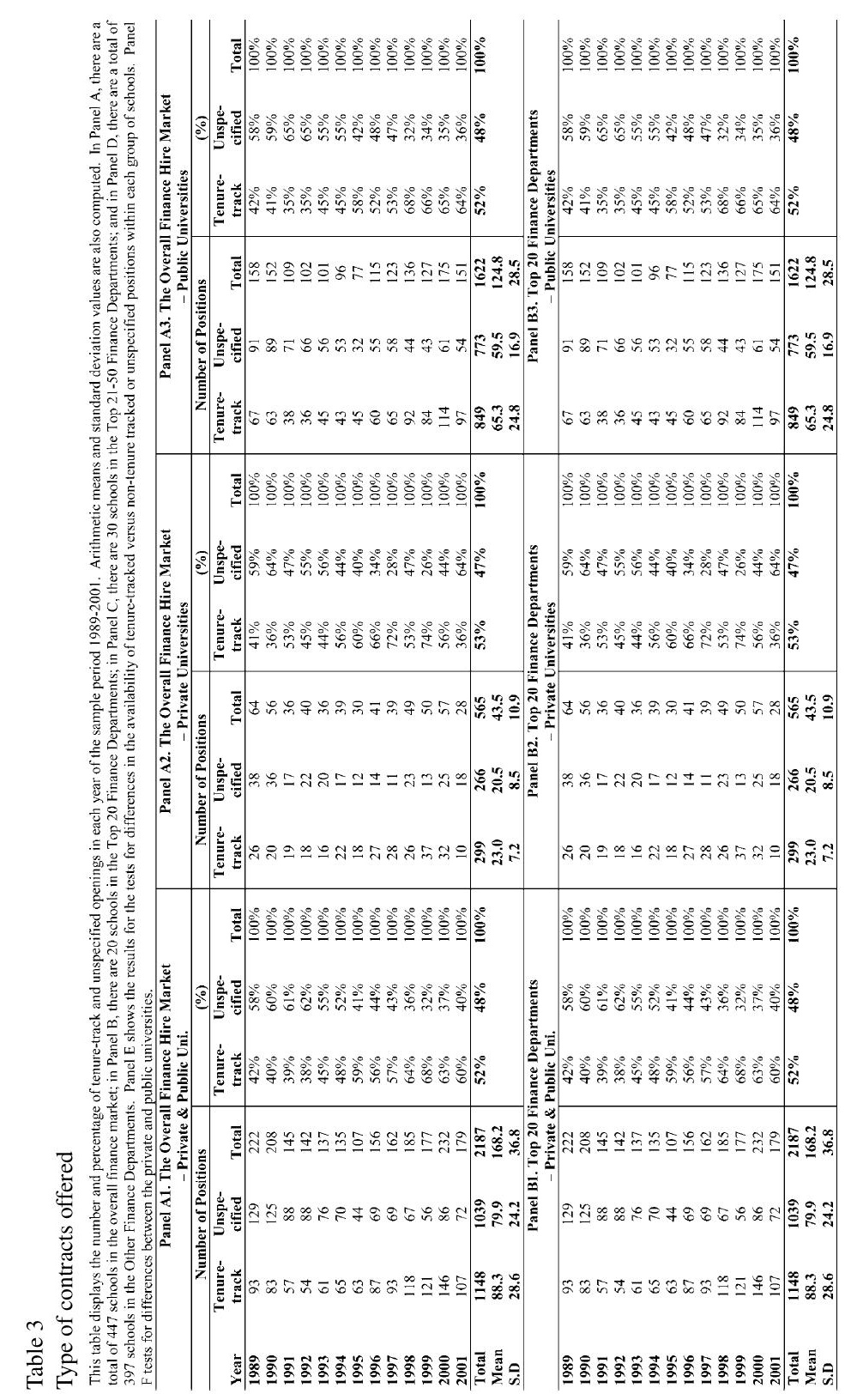




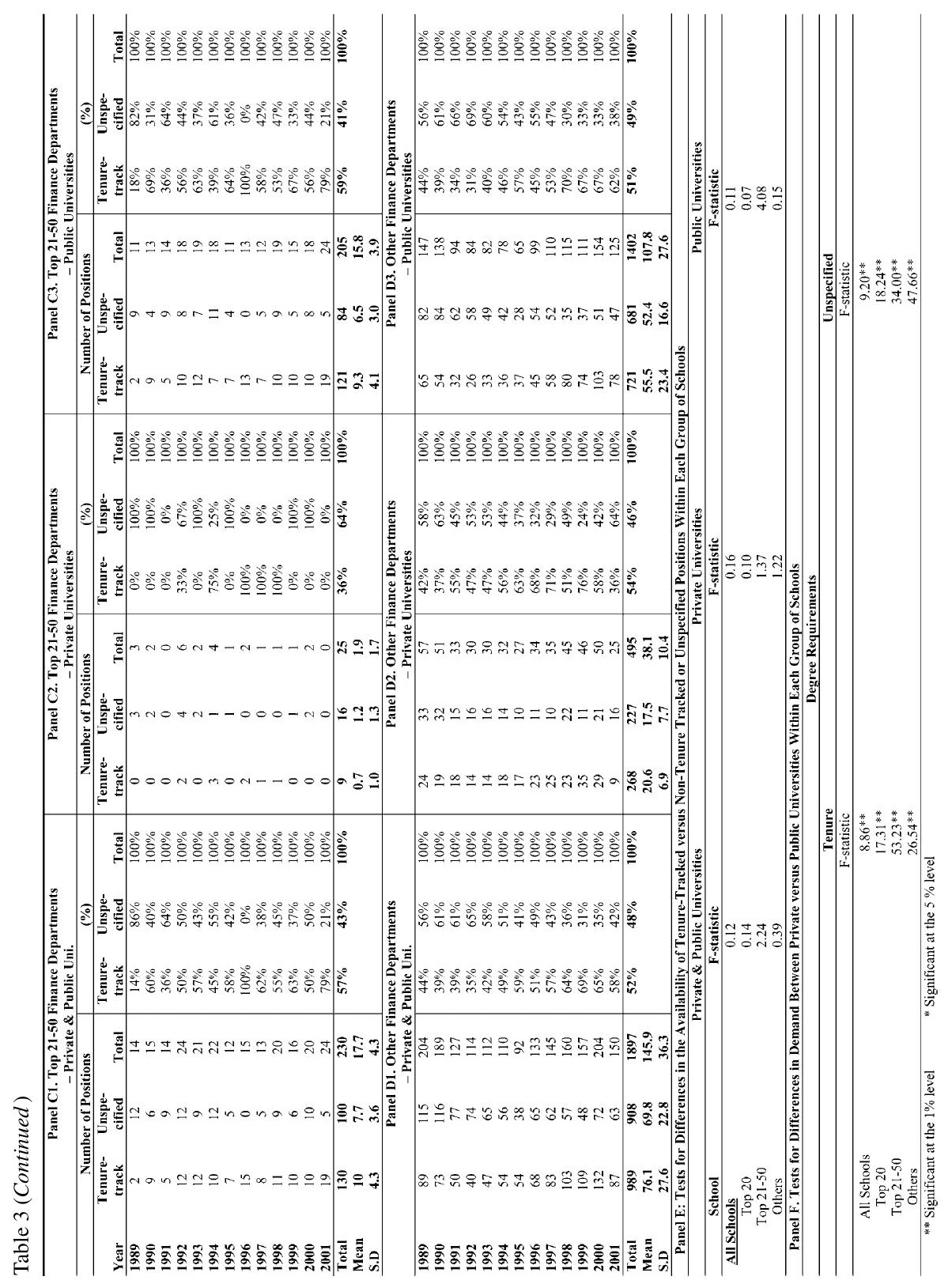




\subsection{Areas of expertise required}

\subsubsection{Overall finance hire market}

In an average year, there are 375 positions advertised (Table 4, Panel A1) and each opening requires candidates to possess an average of 2.2 areas of expertise. ${ }^{6}$ This implies that a new candidate seeking faculty employment should have at least two areas of expertise to increase their chances of receiving an offer. The area of expertise required seems fairly stable with no apparent trends. Table 4, Panel A1, shows that the top three areas of expertise highly demanded among all schools over 1989-2001 are in corporate/business finance (25 percent), investments (19 percent), and bank management/FMI (16 percent). This trend is similar at both private and public universities (Table 4, Panel A2 and A3) in that the three most desired expertise account for at least 60 percent of the total demand.

\subsubsection{Top 20 finance departments}

We note from Table 4, Panel B1, that the average number of expertise areas per opening demanded by the Top 20 Finance Departments is 2.2. Over the 13-year-period, there is no particular demand in the areas of derivative securities, health finance, entrepreneurship, and econometrics. Although one might have expected derivative securities to be an area of expertise desired by these institutions, our results do not concur. It is likely that the derivatives area is considered by the institutions within the broader field of investments and not a separate area of expertise in finance.

The four most highly demanded specific areas of expertise by the Top 20 hiring institutions (see Table 4, Panel B1) are in investments (25 percent), corporate/business finance (24 percent), open category (20 percent) and bank management/FMI (18 percent). These results are consistent with our expectations that, when the global financial markets become more integrated, the demand for professors with their areas of expertise in these areas will increase. Over the whole 13-year-period, the total number of openings is 132, with 1989 having the highest number of openings at 16 and the lowest at six in 1995. During this period, only two ( 2 percent) openings did not specify the areas of expertise desired. Corporate/Business finance ( 25 percent) and investments (27 percent) are the two most desired areas of expertise for the private schools in the Top 20 Finance Departments (Table 4, Panel B2), whereas, the open category ( 35 percent) is the most highly demanded among the top 20 public institutions.

\subsubsection{Top 21-50 finance departments}

Among the Top 21-50 Finance Departments, there are totally no advertised openings seeking candidates with expertise in health finance, and entrepreneurship (Table 4, Panel C1). There also exists no demand for expertise in insurance in 10 of the sample years. In the earlier half of the sample period (1989-1994), the two most desired expertise areas are corporate/business finance and investments. On average, the three most desired areas of expertise by the Top 21-50 Finance Departments are in corporate/business finance (23 percent), investments (23 percent), and bank management/financial markets and institutions (17 percent). In total, there are 519 openings within this group over the 13 -year-period, with 1998 having the highest number of openings at 56 and the lowest at 23 in 1989 and 1991.

\footnotetext{
6 The total of 4874 areas of expertise from Table 4, Panel A1, is divided by the total number of available openings (2187) in Table 1, Panel A1, to give an average of 2.2 areas of expertise per opening.
} 


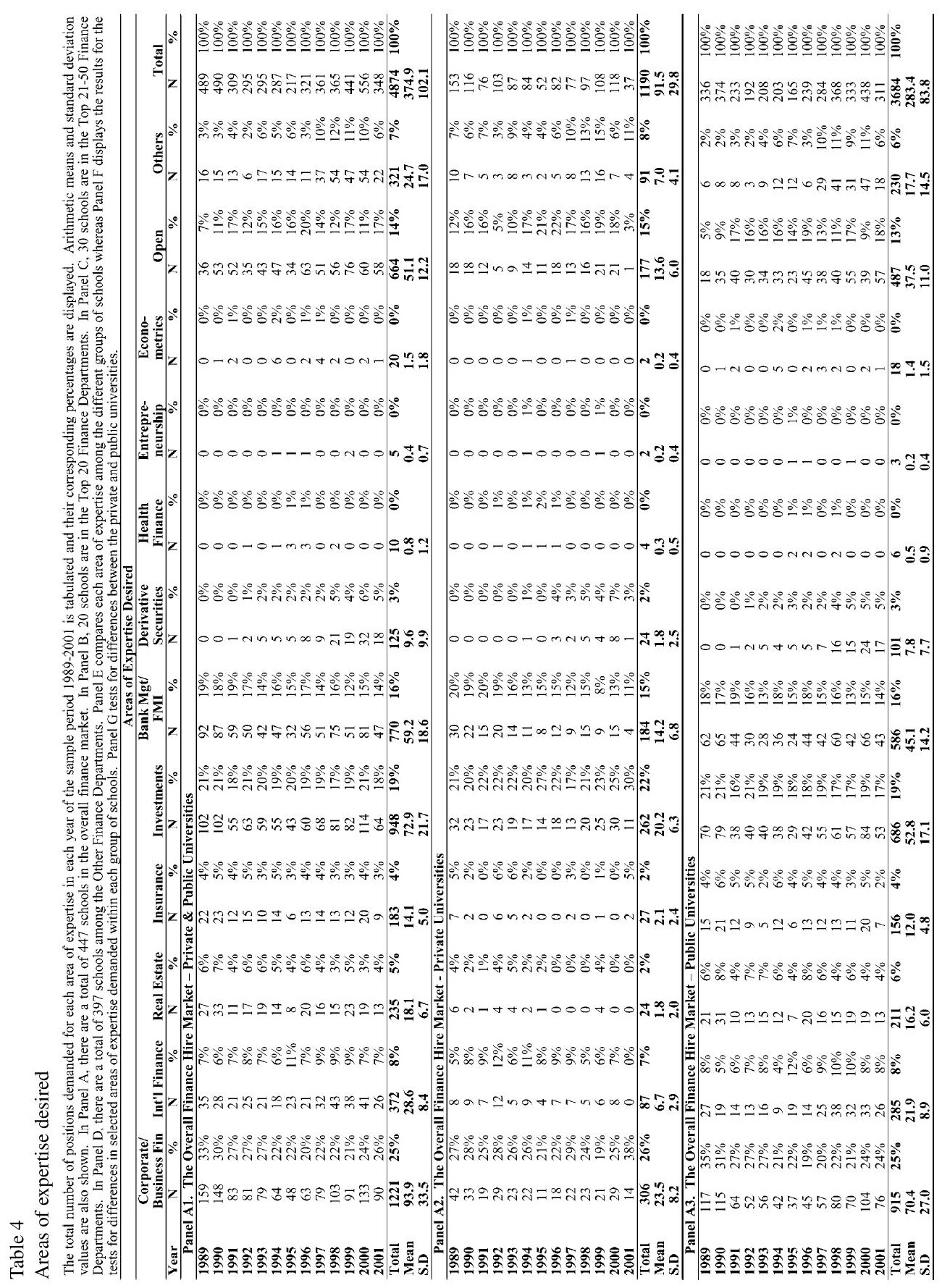




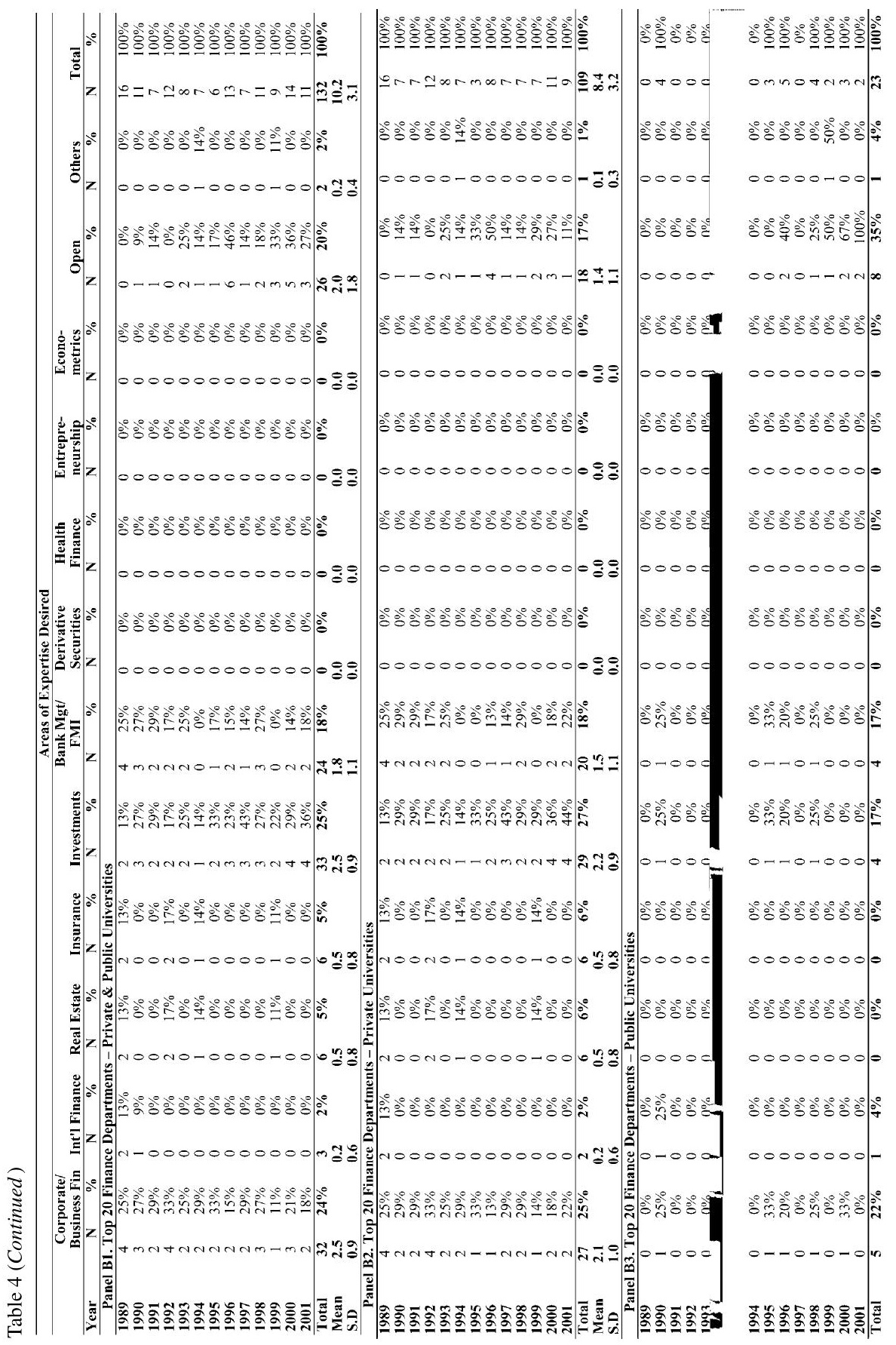




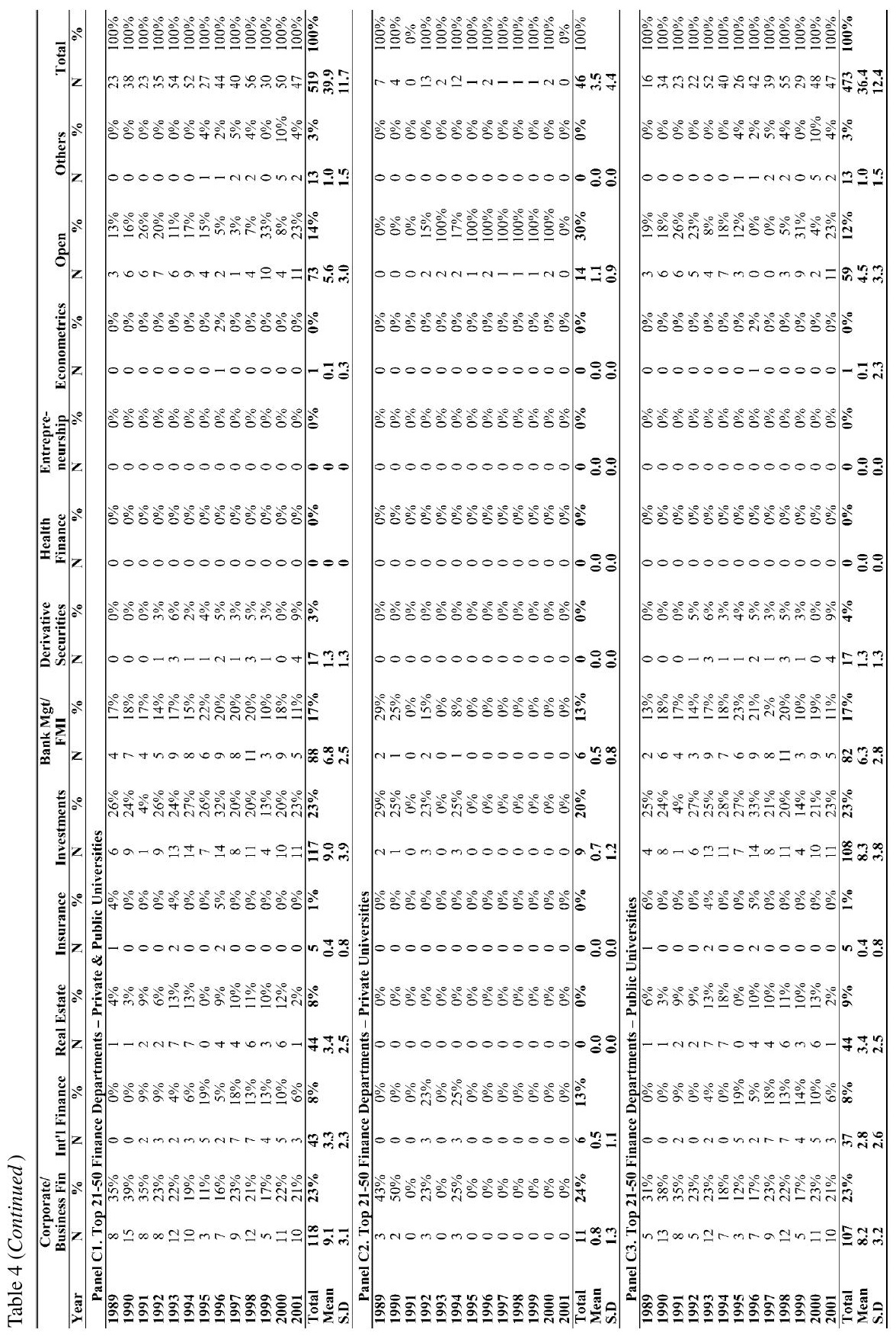




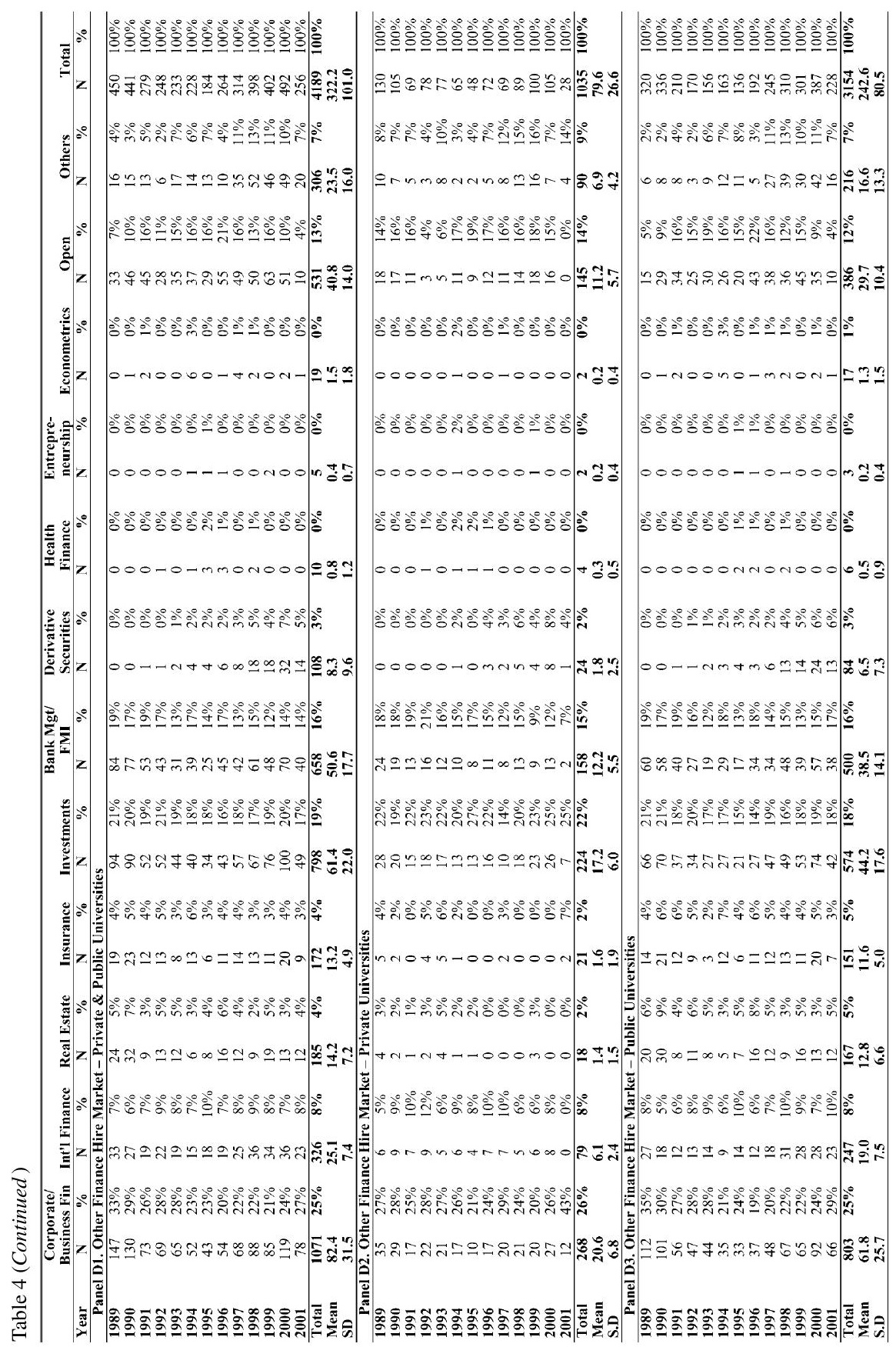




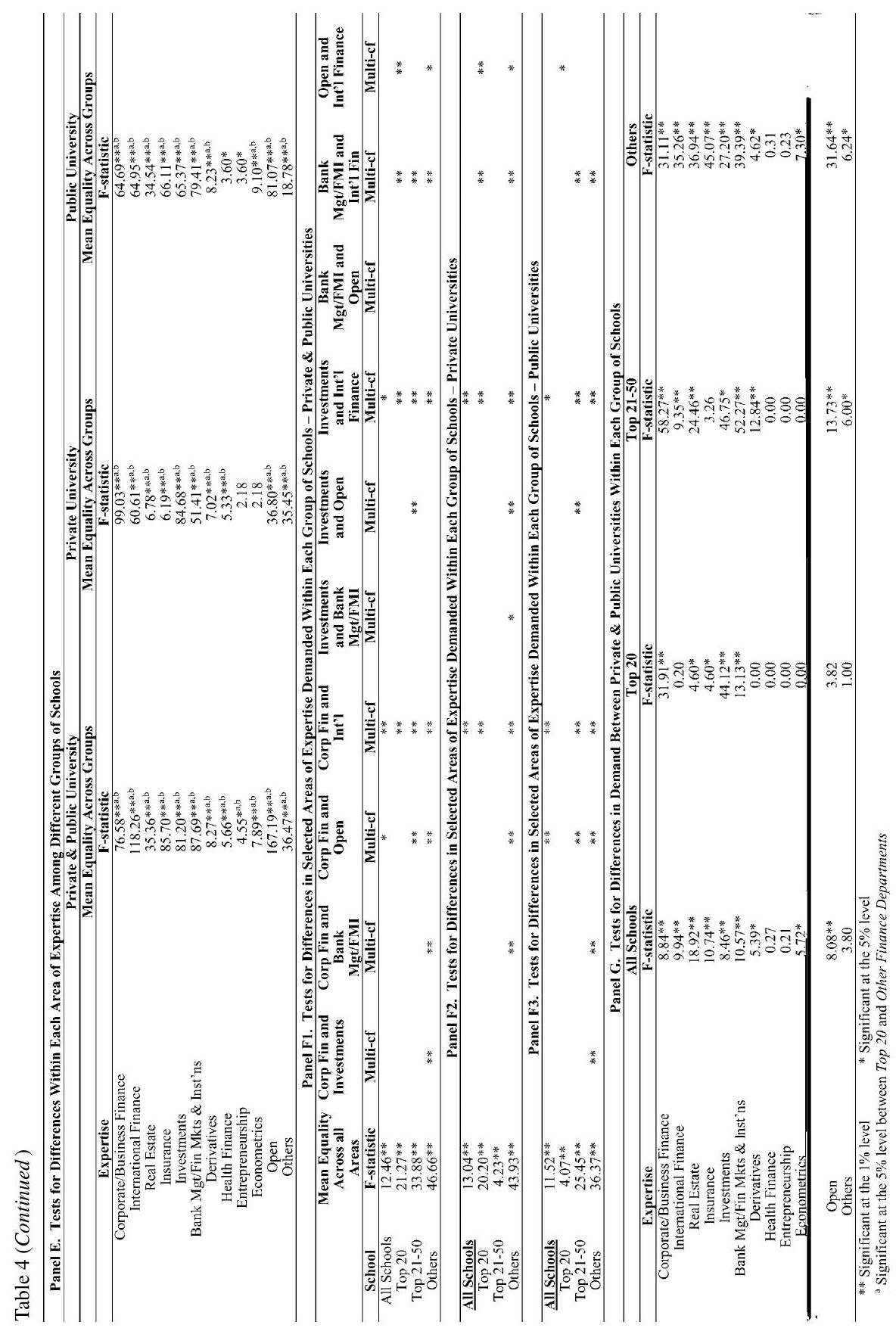


Open positions, where the area of expertise is not specified, accounts for 73 openings (14 percent). Table 4, Panel C 2 and C3 provide the breakdown of the areas of expertise demanded by the Top 21-50private and public schools.

\subsubsection{Other finance departments}

In the Other group (Table 4, Panel D1), corporate/business finance (25 percent), investments (19 percent), and bank management/FMI (16 percent), are the same three areas that employers look for. This is followed by international finance, real estate, and insurance, albeit at a lower frequency. Health finance, entrepreneurship, and econometrics are demanded by a negligible number of institutions. Very often, employers prefer candidates with at least two areas of expertise that includes at least one of the four most popular areas of specialization. Over 1989-2001, there are 4189 openings in this group, with 2000 having the highest number at 492 and the 1995 the lowest 184. There are 306 openings that do not specify a particular area of expertise, representing seven percent of the total openings for this category of schools. Table 4, Panel D2 and D3 show that corporate/business finance, investments, and bank management/FMI account for about 60 percent of the total demand.

The results support our hypothesis that the demand for graduates who specialize in corporate/business finance, investments or financial markets and institutions is stronger than the demand for those who specialize in other areas of finance. The demand for these three areas of expertise accounts for about 60 percent of the total demand.

\subsubsection{Comparison across school types}

The results for Table 4, Panel E1, E2 and E3 show significant differences among the three groups of schools across all expertise, with the exception of entrepreneurship and econometrics for the private universities. The Tukey's multiple-comparison test tells us that the demand is significantly different between the Top 20 and Other groups of schools, as well as between the Top 21-50 and Other groups of schools. There is basically no difference between the Top 20 and the Top 21-50 schools in their demand for the different areas of specialization.

Table 4, Panel F1, F2, and F3 show significant difference among selected areas of expertise across the three groups of schools. The results are significant at the 1 percent level. The multiple-comparison test shows that the differences come mainly from the difference in demand between corporate finance and the open specialization, corporate finance and international finance, investments and international finance, and bank management/FMI and international finance. There is little or no significant difference between investments and bank management/FMI, and bank management/FMI and the open areas of expertise across the three categories of private and public universities.

Table 4, Panel G shows significant differences in all areas of expertise demanded between the private and the public universities across all groups of schools, except for health finance, entrepreneurship, and others. Specifically, their demand for corporate/business finance, real estate, investments, bank management/FMI, and derivatives differ within each group of school.

There is significant difference among the three groups of schools in terms of the areas of expertise they require. There is also significant difference among the areas of expertise within the three groups of schools. Furthermore, private and public universities have different demand for the various areas of expertise. Despite these differences, corporate/business 
finance, investments, and bank management/FMI are still the three most highly demanded specializations.

\subsection{Relationship between the economy and the academic job market}

We employ three variables, namely the Gross Domestic Product (GDP), the unemployment rate (UNM), and the Dow Jones Industrial Average (DJ) to represent the overall performance of the economy. The higher the GDP, the lower the unemployment rate and the higher the stock index as represented by DJ, the better the health of the economy. From the correlation matrix in Table 5, all three variables are highly correlated with each other. In the analysis, we control for the year, the type of university (private or public), as well as the ranking of schools.

We use 12 models to investigate the relationship between the economy and the total academic demand for finance Ph.D. holders (Table 6, Panel A) as well as the relationship between the economy and the demand for entry-level positions (Table 6, Panel B). The first four models investigate the relationship between the demand for finance academics and GDP, while controlling for the year, the school type and ranking. The next four investigate the relationship with the unemployment level. Similar, the last four examine the relationship between the demand for Ph.D.s and the performance of the stock market index.

The results for all the 12 models are significant at the 1 percent level. The first four models show that the total demand for finance Ph.D.s as well as for entry-level positions is positively related to GDP. The higher the GDP, the better is the economy performing and the higher the demand for finance Ph.D.s. Of the four models, Model 3 is the most significant. It has the highest adjusted $R$-squared and $F$-statistic values. The $t$-statistic of $\mathrm{GDP}_{t}$ is significant at the 5 percent level. This shows that the higher the GDP is in a year, the more finance academics will be demanded that year.

In models 5-8, the total demand of finance Ph.D.s is negatively related to the unemployment level of the economy. The lower the unemployment level, the better the performance of the economy and the higher the demand for finance academics. Similarly, models 9-12 show a positive impact from the performance of the stock market on the total demand as well as the entry-level demand of finance Ph.D.s. The better the stock market performs, the better the economy performs, and the higher the demand for finance academics. Model 10 is the most significant in this set of models. It displays the highest adjusted $R$-squared as well as the highest $F$-value. The $t$-statistic of $\mathrm{DJ}_{t-1}$ is also significant at the 5 percent level. This is not surprising because the stock market tends to react faster than the real market. The positive performance of the economy will be first reflected in the stock market before it is reflected in the GDP level. This is because the real market is more rigid and takes a longer time to react to positive news.

All three sets of models present a consistent result. The better the health of the economy, the more finance Ph.D.s are being demanded. This supports our hypothesis that a rising economy should be associated with a higher demand for finance faculty. The results show no significant difference across the years in the number of finance professors demanded. The coefficient of PPDum in all models is significant at the 1 percent level. This shows that there is a difference in the demand between the public and private universities for finance Ph.D.s. The public universities have a greater demand for finance academics when 


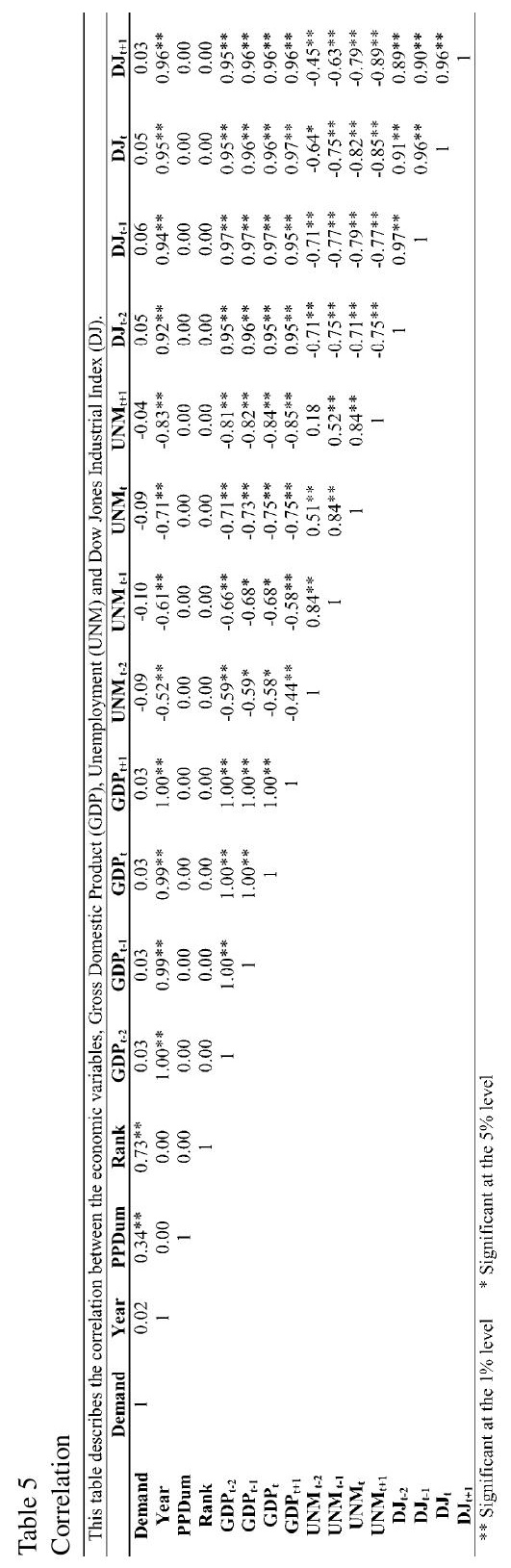




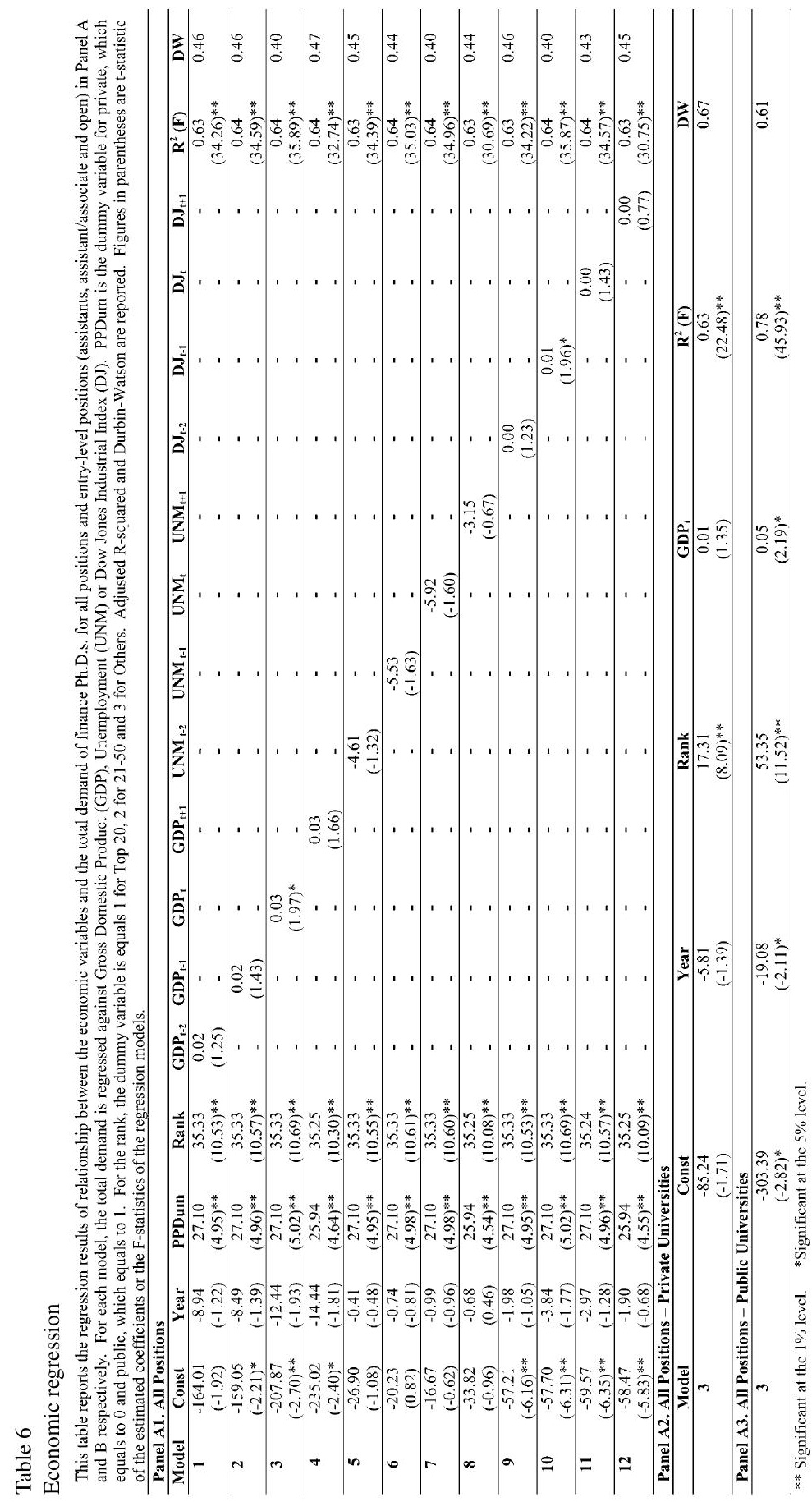




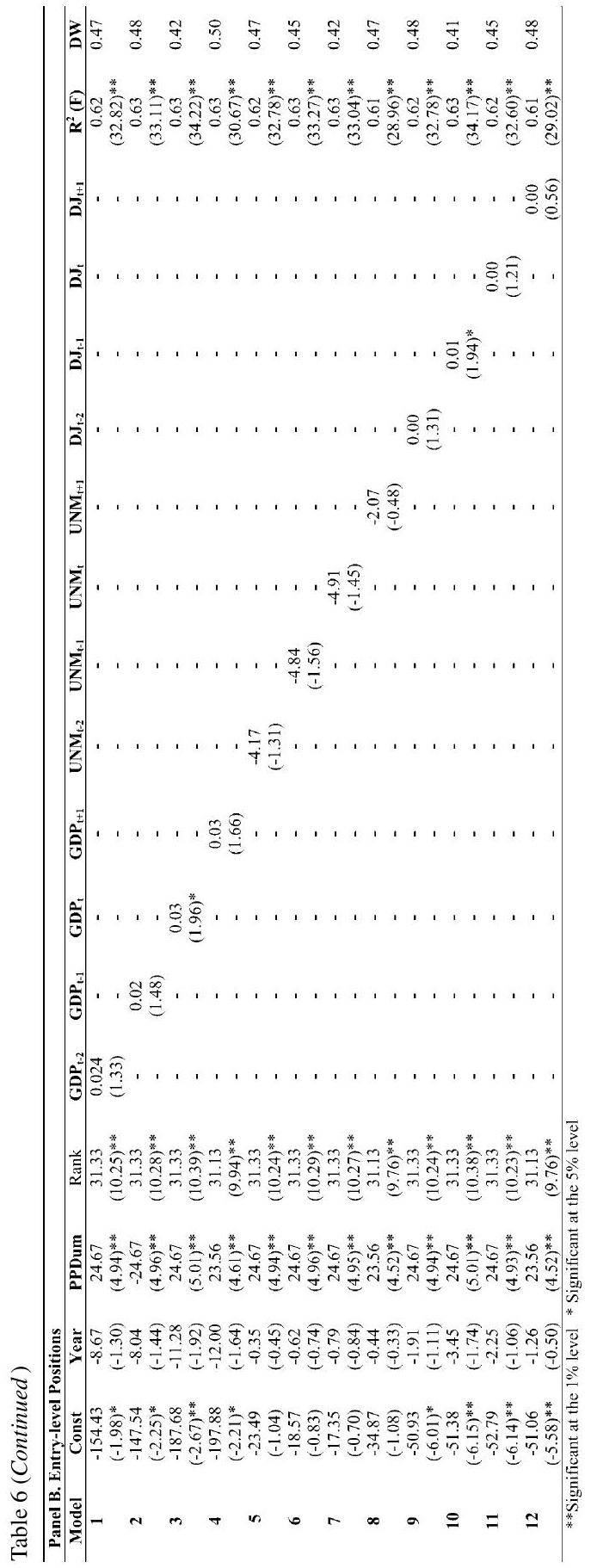


the economy is doing well as compared to the private universities. This is consistent with our hypothesis. When the economy is doing well, the government will have more funds that can be channelled to the public universities. With a larger budget, the public universities will have the financial capability to hire more professors, resulting in a larger demand for finance academics. The results for the rank of schools are all significant at the 1 percent level, where the lower the ranking of schools, the higher the demand for finance Ph.D.s.

\section{Conclusion}

This study examines the market demand for finance Ph.D.s over a 13-year-period from 1989 to 2001. Information on the number of positions available, areas of specialization, availability of tenure-track positions, and degree requirements is obtained from data compiled in the FMA's Directory of Positions Available, Financial Management, the Journal of Business, and the Journal of Finance. Knowledge of these factors is useful for finance Ph.D.s in obtaining a better match between their qualifications and expertise, and available positions. Those with an interest in doctoral education will also have better information on the state of the academic job market. University administrators should find our results useful for a better understanding of the marketplace, including the knowledge of how their competitors are hiring. Furthermore, the study offers a basis for comparing institutional practices.

In the overall finance hire market, 60 percent of the total positions advertised are for assistant professors and assistant/associate professors. Open positions represent 30 percent of the total in the 13-year-period of the study. It is observed that job openings for positions excluding assistant professors represent only 11 percent of the total number advertised over the 13 years. There are differences in their demand for the Assistant/Associate rank and in their demand for the Open rank among the private and public universities. There is a majority of 60 percent of the hiring institutions that want candidates with an earned Ph.D. There is a significant difference among the private and public universities' demand for candidates' degree requirements. Out of the total openings in our sample period, it is observed that 52 percent of them are tenure-track ones. However, this percentage varies from year to year. There is a significant difference in the types of contracts advertised for by the private and the public universities. The most desired areas of expertise are in corporate/business finance, investments, and bank management/FMI. A new candidate seeking a faculty appointment needs more than two areas of expertise to have higher chances of receiving an offer. The areas of expertise required by the hiring institutions seem fairly stable, with no distinguishing upward or downward trend. Among the three groups of schools across all expertise, there is a significant difference among the Top 20 and Other group of schools and among the Top 21-50 and Other group of schools. The demand of finance Ph.D. is positively related to the level of GDP and the stock market represented by the Dow Jones, but is negatively related to the level of unemployment.

\section{Acknowledgements}

The authors acknowledge the helpful suggestions and comments from Louis Cheng and participants of the NTU Finance Faculty Workshop and the 2000 FMA Conference. 


\section{Appendix A}

The universities are ranked based on Fishe's (1998) total impact of research criterion. There are a total of 447 universities in this list, of which 397 are classified under the $O$ ther category. The private universities are in bold.

\begin{tabular}{|c|c|c|c|}
\hline \multicolumn{2}{|c|}{ Top 20 Finance Departments } & \multicolumn{2}{|c|}{ Top 21-50 Finance Departments } \\
\hline Rank & Name of College or University & Rank & Name of College or University \\
\hline 1 & New York University - Stern School of Business & 21 & Arizona State University \\
\hline 2 & University of Chicago & 22 & University of Illinois \\
\hline 3 & University of Pennsylvania - Wharton & 23 & University of Georgia \\
\hline 4 & University of Michigan & 24 & University of Texas at Austin \\
\hline 5 & Harvard University & 25 & Southern Methodist University \\
\hline 6 & University of California - Los Angeles & 26 & Louisiana State University \\
\hline 7 & Ohio State University & 27 & University of Florida \\
\hline 8 & Northwestern University & 28 & Virginia Tech. University \\
\hline 9 & University of Rochester & 29 & Vanderbilt University \\
\hline 10 & Duke University & 30 & Rutgers University \\
\hline 11 & Columbia University & 31 & Washington University \\
\hline 12 & MIT - Sloan School of Business & 32 & Purdue University \\
\hline 13 & University of British Columbia & 33 & University of Wisconsin - Madison \\
\hline 14 & Stanford University & 34 & Yale University \\
\hline 15 & University of Southern California & 35 & University of California - Berkeley \\
\hline 16 & Cornell University & 36 & City University of New York - Baruch College \\
\hline 17 & Boston College & 37 & University of North Carolina - Chapel Hill \\
\hline 18 & Indiana University & 38 & University of Maryland - College Park \\
\hline 19 & University of Washington & 39 & University of California - Irvine \\
\hline \multirow[t]{11}{*}{20} & Carnegie Mellon University & 40 & Dartmouth College - Tuck \\
\hline & & 41 & Texas A\&M University \\
\hline & & 42 & University of Minnesota - Twin Cities \\
\hline & & 43 & Notre Dame University \\
\hline & & 44 & Boston University \\
\hline & & 45 & Clemson University \\
\hline & & 46 & Iowa State University \\
\hline & & 47 & University of Virginia \\
\hline & & 48 & Pennsylvania State University - University Park \\
\hline & & 49 & Southern Illinois University - Edwardsville \\
\hline & & 50 & Texas Tech. University \\
\hline \multirow{2}{*}{\multicolumn{2}{|c|}{ Other Finance Departments (in alphabetical order) }} & 201 & Sam Houston State University \\
\hline & & 202 & San Diego State University-Imperial Valley \\
\hline \multirow{2}{*}{ Rank } & Name of College or University & 203 & San Francisco State University \\
\hline & & 204 & San Jose State University \\
\hline 1 & American University & 205 & Santa Clara University \\
\hline 2 & Appalachian State University & 206 & Seattle University \\
\hline 3 & Arizona State University West & 207 & Seton Hall University \\
\hline 4 & Arkansas State University & 208 & Shippensburg University \\
\hline 5 & Auburn University & 209 & Siena College \\
\hline 6 & Augustana College & 210 & Simmons College \\
\hline 7 & Babson College & 211 & Simon Fraser University \\
\hline 8 & Ball State University & 212 & Skidmore College \\
\hline 9 & Baylor University & 213 & Sophia University \\
\hline 10 & Belmont University & 214 & Southeast Missouri State University \\
\hline 11 & Bentley College & 215 & Southeastern Louisiana University \\
\hline 12 & Bloomsberg University of Pennsylvania & 216 & Southeastern Oklahoma State University \\
\hline 13 & Bowling Green State University & 217 & Southern Connecticut State University \\
\hline 14 & Bradley University & 218 & Southern Illinois University - Carbondale \\
\hline 15 & Brock University & 219 & Southwest Missouri State University \\
\hline 16 & Bryant College & 220 & Southwest Texas State University \\
\hline 17 & Bucknell University & 221 & State University of New York - Albany \\
\hline 18 & Butler University & 222 & State University of New York - Baffalo \\
\hline 19 & California Polytechnic State University - Pomona & 223 & State University of New York - Birghamton \\
\hline 20 & California Polytechnic State University - San Luis & 224 & State University of New York - New Paltz \\
\hline 21 & California State University - Chico & 225 & State University of New York - Utica/ Rome \\
\hline 22 & California State University - Fresno & 226 & Stetson University \\
\hline 23 & California State University - Fullerton & 227 & St. Bonaventure University \\
\hline 24 & California State University - Hayward & 228 & St. John Fisher College \\
\hline 25 & California State University - Long Beach & 229 & St. John's University \\
\hline 26 & California State University - Los Angeles & 230 & St. Joseph's University \\
\hline 27 & California State University - Northridge & 231 & St. Louis University \\
\hline 28 & California State University - San Bernardino & 232 & St. Mary's University \\
\hline 29 & California State University - San Marcos & 233 & St. Norbert College \\
\hline
\end{tabular}




\begin{tabular}{|c|c|c|c|}
\hline 30 & Canisius College & 234 & Stonehill College \\
\hline 31 & Capital University & 235 & Suffolk University \\
\hline 32 & Case Western Reserve University & 236 & Syracuse University \\
\hline 33 & Catholic University of America & 237 & Tennessee Technological University \\
\hline 34 & Cedarville University & 238 & Temple State University \\
\hline 35 & Central Connecticut State University & 239 & Texas A\&M International University \\
\hline 36 & Central Michigan University & 240 & Texas Christian University \\
\hline 37 & Central Missouri State University & 241 & The American College \\
\hline 38 & Chapman University & 242 & The Chinese University of Hong Kong \\
\hline 39 & City University of Hong Kong & 243 & The College of Charleston \\
\hline 40 & City University of New York - Hunter College & 244 & The George Washington University \\
\hline 41 & Claremont Graduate University & 245 & Towson University \\
\hline 42 & Claremont Mckenna College & 246 & Trenton State College \\
\hline 43 & Clark University & 247 & Tulane University \\
\hline 44 & Clarkson University & 248 & Union College \\
\hline 45 & Cleveland State University & 249 & Universidad Autonoma de Bucaramanga \\
\hline 46 & College of St. Thomas & 250 & Universite De Lausanne \\
\hline 47 & College of William and Mary & 251 & University College of the Cariboo \\
\hline 48 & Colorado State University & 252 & University of Akron \\
\hline 49 & Columbus State University & 253 & University of Alabama \\
\hline 50 & Concordia University & 254 & University of Alabama - Birmingham \\
\hline 51 & Copenhagen Business School & 255 & University of Alabama - Huntsville \\
\hline 52 & Creighton University & 256 & University of Alberta \\
\hline 53 & Dalhousie University & 257 & University of Arizona \\
\hline 54 & Delta State University & 258 & University of Arkansas \\
\hline 55 & DePaul University & 259 & University of Arkansas - Little Rock \\
\hline 56 & Dowling College & 260 & University of Auckland \\
\hline 57 & Drake University & 261 & University of Baltimore \\
\hline 58 & Drexel University & 262 & University of Bridgeport \\
\hline 59 & Dublin City University & 263 & University of Calgary \\
\hline 60 & Duquesne University & 264 & University of Central Arkansas \\
\hline 61 & East Carolina University & 265 & University of Central Florida \\
\hline 62 & Eastern Connecticut State University & 266 & University of Cincinnati \\
\hline 63 & Eastern Illinois University & 267 & University of Colorado - Boulder \\
\hline 64 & Eastern Kentucky University & 268 & University of Colorado - Colorado Springs \\
\hline 65 & Eastern Michigan University & 269 & University of Colorado - Denver \\
\hline$\ll<$ & $\boldsymbol{r} \ldots$ & חר & 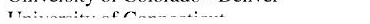 \\
\hline
\end{tabular}




\begin{tabular}{|c|c|c|c|}
\hline 102 & Idaho State University & 306 & University of Montreal \\
\hline 103 & Illinois Institute of Technology & 307 & University of Nebraska - Lincoln \\
\hline 104 & Illinois State University & 308 & University of Nebraska- Omaha \\
\hline 105 & Illinois Wesleyan University & 309 & University of Nevada - Las Vegas \\
\hline 106 & Illinois Institute of Technology & 310 & University of Nevada - Reno \\
\hline 107 & Illinois State University & 311 & University of New Hampshire \\
\hline 108 & Indian Institute of Management - Bangalore & 312 & University of New Mexico \\
\hline 109 & Indian Institute of Management - Lucknow & 313 & University of New Orleans \\
\hline 110 & Indiana State University & 314 & University of New South Wales \\
\hline \multirow[t]{2}{*}{111} & INSEAD (European Institute of Business & 315 & University of North Carolina - Charlotte \\
\hline & Administration) & 316 & University of North Carolina - Pembroke \\
\hline 112 & Instituto De Empresa & 317 & University of North Carolina - Wilmington \\
\hline 113 & Instituto Technologico Autonoma De Mexico & 318 & University of Northern Colorado \\
\hline 114 & International University of Japan & 319 & University of Northern lowa \\
\hline 115 & James Madison University & 320 & University of North Florida \\
\hline 116 & John Caroll University & 321 & University of North Texas \\
\hline 117 & Kalamazoo College & 322 & University of Notre Dame \\
\hline 118 & Kansas State University & 323 & University of Oklahoma- Norman \\
\hline 119 & Kennesaw State University & 324 & University of Otago \\
\hline 120 & Kent State University & 325 & University of Pacific \\
\hline 121 & King Fahd University of Petroleum \& Minerals & 326 & University of Pittsburgh \\
\hline 122 & King's College & 327 & University of Portland \\
\hline 123 & Koç University & 328 & University of Puget Sound \\
\hline 124 & Lander University & 329 & University of Reading \\
\hline 125 & Laredo State University & 330 & University of Regina \\
\hline 126 & LaSalle University & 331 & University of Rhode Island \\
\hline 127 & Laval University & 332 & University of Richmond \\
\hline 128 & Lehigh University & 333 & University of San Diego \\
\hline 129 & Long Island University & 334 & University of San Francisco \\
\hline 130 & Louisiana State University & 335 & University of Saskatchewan \\
\hline 131 & Louisiana Tech. University & 336 & University of Scranton \\
\hline 132 & Loyola College in Maryland & 337 & University of South Alabama \\
\hline 133 & Loyola Marymount University & 338 & University of South Carolina \\
\hline 134 & Loyola University of Chicago & 339 & University of South Florida - Tampa \\
\hline 135 & Madrid Business School & 340 & University of Southern Indiana \\
\hline 136 & Marquette University & 341 & University of Southern Maine \\
\hline 137 & Marshall University & 342 & University of Southern Mississippi \\
\hline 138 & Massey University & 343 & University of Strathclyde \\
\hline 139 & McGill University & 344 & University of St. Thomas \\
\hline 140 & McMaster University & 345 & University of Tampa \\
\hline 141 & McNeese State University & 346 & University of Technology - Sydney \\
\hline 142 & Memorial University of Newfoundland & 347 & University of Tennessee - Chattanooga \\
\hline 143 & Mercer University & 348 & University of Tennessee - Knoxville \\
\hline 144 & Metropolitan State College of Denver & 349 & University of Tennessee - Martin \\
\hline 145 & Miami University & 350 & University of Texas - Arlington \\
\hline 146 & Michigan State University & 351 & University of Texas - Dallas \\
\hline 147 & Michigan Technological University & 352 & University of Texas - El Paso \\
\hline 148 & Minnesota State University - Moorhead & 353 & University of Texas - Pan American \\
\hline 149 & Mississippi State University & 354 & University of Texas - San Antonio \\
\hline 150 & Monmouth University & 355 & University of Texas - Tyler \\
\hline 151 & Montclair State University & 356 & University of Toledo \\
\hline 152 & Moorhead State University & 357 & University of Toronto \\
\hline 153 & Murray State University & 358 & University of Tulsa \\
\hline 154 & Nanyang Technological University & 359 & University of Utah \\
\hline 155 & National Central University & 360 & University of Vermont \\
\hline 156 & National Chengchi University & 361 & University of Victoria \\
\hline 157 & National Chung Cheng University & 362 & University of Waikato \\
\hline 158 & National University of Singapore & 363 & University of Western Ontario \\
\hline 159 & National Yunlin University of Science \& Technology & 364 & University of Western Sydney \\
\hline 160 & New College of the University of South Florida - & 365 & University of Windsor \\
\hline & Savasota & 366 & University of Wisconsin - Eau Claire \\
\hline 161 & New Mexico State University & 367 & University of Wisconsin - Green Bay \\
\hline 162 & Niagara University & 368 & University of Wisconsin - Lacrosse \\
\hline 163 & North Carolina State University & 369 & University of Wisconsin - Milwaukee \\
\hline 164 & Northeastern Illinois University & 370 & University of Wisconsin - Oshkosh \\
\hline 165 & Northeastern University & 371 & University of Wisconsin - Parkside \\
\hline 166 & Northern Arizona University & 372 & University of Wisconsin - Whitewater \\
\hline 167 & Northern Illinois University & 373 & University of Wyoming \\
\hline 168 & Northern Michigan University & 374 & Valparaiso University \\
\hline 169 & North Georgia College and State University & 375 & Villanova University \\
\hline 170 & Norwegian School of Management & 376 & Virginia Commonwealth University \\
\hline 171 & Nova Southeastern University & 377 & Wake Forest University \\
\hline
\end{tabular}




\begin{tabular}{|c|c|c|c|}
\hline 172 & Oakland University & 378 & Washburn University of Topeka \\
\hline 173 & Ohio University & 379 & Washington and Lee University \\
\hline 174 & Old Dominion University & 380 & Washington State University \\
\hline 175 & Oklahoma City University & 381 & Wayne State University \\
\hline 176 & Oklahoma State University & 382 & West Chester University \\
\hline 177 & Oregon State University & 383 & West Virginia University \\
\hline 178 & Otterbein College & 384 & Western Carolina University \\
\hline 179 & Pace University & 385 & Western Illinois University \\
\hline 180 & Peking University & 386 & Western Kentucky University \\
\hline 181 & Penn State Erie & 387 & Western Michigan University \\
\hline 182 & Penn State Great Valley & 388 & Western New England College \\
\hline 183 & Penn State Harrisburg & 389 & Western Washington University \\
\hline 184 & Pepperdine University & 390 & Wichita State University \\
\hline 185 & Philadelphia College of Textiles \& Science & 391 & Wilfred Laurier University \\
\hline 186 & Portland State University & 392 & Winona State University \\
\hline 187 & Price College of Business & 393 & Wintrop University \\
\hline 188 & Queen's University & 394 & Worcester Polytechnic Institute \\
\hline 189 & Quinnipiac University & 395 & Xavier University \\
\hline 190 & Radford University & 396 & York University \\
\hline 191 & Rensselaer Polytechnic Institute & 397 & Yuan Ze University \\
\hline 192 & Rhodes College & & \\
\hline 193 & Rice University & & \\
\hline 194 & Rider University & & \\
\hline 195 & Rochester Institute of Technology & & \\
\hline 196 & Rollins College & & \\
\hline 197 & Rowan College of New Jersey & & \\
\hline 198 & Ryerson Polytechnic University & & \\
\hline 199 & Sabanci University & & \\
\hline 200 & Salisbury State University & & \\
\hline
\end{tabular}

\section{References}

Agarwal, V., Yochum, G., 2000. The academic labor market for new Ph.D.s in business disciplines. J. Business Econ. Stud. (Fall), 1-21.

Barbezat, D., 1992. The market for new Ph.D. economists. J. Econ. Edu. (Summer), 262-276.

Barkume, M., 1997. The job market for Ph.D.s: two views. Occupat. Outlook Quart. (Winter), 2-15.

Bennett, A., 1994. U.S. universities at an economic crossroads: tenure-many will decry it, few deny it, The Wall Street J. (October).

Bertin, W., Prather, L., Zivney, T., 1999. The new hire market in finance for 1997-1998: salaries and other market factors. Financial Pract. Edu. (Fall/Winter), 81-90.

Bertin, W., Zivney, T., 1991. The new hire market for finance: productivity, salaries and other market factors. Financial Pract. Edu. (Spring), 25-34.

Brown, K., Reilly, F., 2000. Investment Analysis and Portfolio Management. Harcourt, Inc., pp. 156-160.

Carson, R., Navarro, P., 1988. A seller's (and buyer's) guide to the job market for beginning academic economists. J. Econ. Perspectives (Spring), 137-148.

Cheng, L., Davidson, W., 1995. The characteristics of job applicants for finance faculty positions: 1986-1992. Financial Pract. Edu. (Fall/Winter), 18-29.

Claiborn, S., Collins, J., 1978. The entering job market for careers in finance. J. Financial Edu. (Fall), 25-29.

Coble, R., 2001. Trends in higher education: changes in governance. J. State Government (Spring), 16-18.

Dyl, E., 1992. All universities are not created equal: a note on the tiered market for finance academics. Presented at the 1992 Financial Management Association Meetings in San Francisco, CA.

Eaton, T., Nofsinger, J., 2000. The new and relocating finance faculty market: factors affecting job selection. Financial Pract. Edu. (Spring/Summer), 99-110.

Ehrenberg, R., 1992. The flow of new doctorates. J. Econ. Lit. (June), 830-875.

Ehrenberg, R., Kasper, H., Rees, D., 1991. Faculty turnover at American colleges and university. Econ. Edu. Rev., 99-110.

Ehrenberg, R., Pieper, P., Willis, R., 1998. Do economics departments with lower tenure probabilities pay higher faculty salaries. Am. Econ. Rev. (November), 503-512.

Fishe, R., 1998. What are the research standards for full professor of finance. J. Finance (June), 1053-1079.

Freeman, R., 1975. Supply and salary adjustments to the changing science manpower market: physics, 1948-1973. Am. Econ. Rev. (March), 27-39. 
Freeman, R., 1976. A Cobweb model of the supply and starting salary of new engineers. Ind. Labor Rel. Rev. (July), 236-248.

Grablowsky, B., Brewer, B., 1975. The market for finance majors: some myths and some realities. J. Financial Edu. (Fall), 33-36.

Hansen, W., Newberger, H., Schroeder, N., Stapleton, D., Youngday, D., 1980. Forecasting the market for Ph.D. economists. Am. Econ. Rev., 49-63.

Keller, G., Warrack, B., 1999. Statistics for Management and Economics, Pacific Grove, CA, Duxbury Thomson Learning, pp. 480-481.

Lahey, K., Vihtelic, J., 2000. Finance faculty demographics, career history, diversity, and job satisfaction. Financial Pract. Edu. (Spring/Summer), 111-122.

Magner, D., 1999. Universities see slight increase in number of doctorates awarded. Chron. Higher Edu. (November), 18-19.

McCarty, D., Scherer, P., 1977. The demand for finance majors by financial institutions in the southwest. J. Financial Edu. (Fall), 40-44.

Taube, P., MacDonald, D., 1989. The job market for Finance Ph.D.s. J. Financial Edu. (Fall), 54-59.

Tompkins, J., Hermanson, H., Hermanson, D., 1996. Expectations and resources associated with new finance faculty positions. Financial Pract. Edu. (Spring/Summer), 54-63.

Tripathy, N., Ganesh, G., 1996. Evaluation, promotion, and tenure of finance faculty. Financial Pract. Edu. (Spring/Summer), 46-53.

Yemma, J., 1997. Job market does number on Ph.D.s in math, science. Boston Globe (March). 